\title{
A decline in global CFC-11 emissions during 2018-2019
}

https://doi.org/10.1038/s41586-021-03260-5

Received: 1 July 2020

Accepted: 11 December 2020

Published online: 10 February 2021

Check for updates

\begin{abstract}
Stephen A. Montzka ${ }^{1 凶}$, Geoffrey S. Dutton ${ }^{1,2}$, Robert W. Portmann ${ }^{3}$, Martyn P. Chipperfield ${ }^{4,5}$, Sean Davis ${ }^{3}$, Wuhu Feng ${ }^{4,6}$, Alistair J. Manning ${ }^{7}$, Eric Ray ${ }^{2,3}$, Matthew Rigby ${ }^{8}$, Bradley D. Hall', Carolina Siso $^{1,2}$, J. David Nance, ${ }^{1,2}$, Paul B. Krummel ${ }^{9}$, Jens Mühle ${ }^{10}$, Dickon Young ${ }^{8}$, Simon O'Doherty ${ }^{8}$, Peter K. Salameh ${ }^{10}$, Christina M. Harth ${ }^{10}$, Ronald G. Prinn ${ }^{11}$, Ray F. Weiss ${ }^{10}$, James W. Elkins ${ }^{1}$, Helen Walter-Terrinoni ${ }^{12}$ \& Christina Theodoridi ${ }^{13}$
\end{abstract}

\begin{abstract}
The atmospheric concentration of trichlorofluoromethane (CFC-11) has been in decline since the production of ozone-depleting substances was phased out under the Montreal Protocol ${ }^{1,2}$. Since 2013, the concentration decline of CFC-11 slowed unexpectedly owing to increasing emissions, probably from unreported production, which, if sustained, would delay the recovery of the stratospheric ozone layer ${ }^{1-12}$. Here we report an accelerated decline in the global mean CFC-11 concentration during 2019 and 2020, derived from atmospheric concentration measurements at remote sites around the world. We find that global CFC-11 emissions decreased by $18 \pm 6$ gigagrams per year ( $26 \pm 9$ per cent; one standard deviation) from 2018 to 2019 , to a 2019 value $(52 \pm 10$ gigagrams per year) that is similar to the 2008-2012 mean. The decline in global emissions suggests a substantial decrease in unreported CFC-11 production. If the sharp decline in unexpected global emissions and unreported production is sustained, any associated future ozone depletion is likely to be limited, despite an increase in the CFC-11 bank (the amount of CFC-11 produced, but not yet emitted) by 90 to 725 gigagrams by the beginning of 2020 .
\end{abstract}

After the discovery ${ }^{1}$ that global emissions and probably also production of the potent ozone-depleting chemical CFC-11 increased after 2012despite Montreal Protocol controls banning production by 2010scientists, industry experts, policy makers and others sought information to enable rapid mitigation and to ensure protection of the ozone layer $^{2-12}$. Although these efforts added clarity to our understanding, uncertainties remain that could hinder effective and rapid mitigation of the unexpected CFC-11 emissions and prevent reliable estimates of the additional damage expected for the ozone layer. These uncertainties include the total amount of unreported CFC-11 production and how it was used (which determines the CFC-11 'bank', the amount still existing in foams, chillers and so on, that has yet to escape to the atmosphere), the regions responsible for new production, and the extent to which unreported CFC-11 production continues.

At least $40 \%$ to $60 \%$ of the enhancement in global emission during 2014-2017 has been attributed to eastern mainland China ${ }^{3}$. Even before this specific attribution, China conducted internal inspections in late 2018 and 2019 and announced renewed enforcement and enhanced inspection measures as elements of a broad plan to mitigate any illicit CFC production and use ${ }^{13}$. Effective and rapid mitigation of the renewed production and emission probably depends in part on the success of this Chinese initiative. It is difficult to predict its effectiveness for rapidly mitigating global emission enhancements, given that only small amounts of CFC-11 production were discovered in these inspections relative to the observationally derived global and regional emission increase $\mathrm{e}^{3,9,13,14}$, and because the regions responsible for the remaining portion of the global emission increase have yet to be identified ${ }^{3}$.

The most likely use of the newly produced CFC-11 is for manufacturing closed-cell foams ${ }^{4}$. This could imply post-2010 CFC-11 production magnitudes that were as much as two to four times larger than emission enhancements detected to date ${ }^{4}$, and an increase in the total amount of CFC-11 contained in foams worldwide. Leakage of CFC-11 from this global bank or reservoir (1,000-2,000 Gg today ${ }^{3,4,15}$, including lesser amounts in chillers) sustains emissions of CFC-11 and is one reason why CFC-11 concentrations (or mole fractions) have not diminished as rapidly as most other gases following production phase-outs. Whereas emissions from this reservoir are expected to decrease gradually over time as this reservoir becomes depleted by leakage $e^{4,15,16}$, substantial use of newly produced CFC-11 in insulating foams would enhance emissions for many years even after production was stopped. Accordingly, the ultimate impact of the renewed use of CFC-11 on the ozone layer will be larger than the emission enhancement detected so far, as it will depend on the cumulative amount of unreported production, which is not known.

In the absence of an accurate accounting of production and use of CFC-11 since 2010, atmospheric measurements at sites around the

${ }^{1}$ Global Monitoring Laboratory, National Oceanic and Atmospheric Administration, Boulder, CO, USA. ${ }^{2}$ Cooperative Institute for Research in Environmental Sciences, University of Colorado, Boulder, CO, USA. ${ }^{3}$ Chemical Sciences Laboratory, National Oceanic and Atmospheric Administration, Boulder, CO, USA. ${ }^{4}$ School of Earth and Environment, University of Leeds, Leeds, UK.

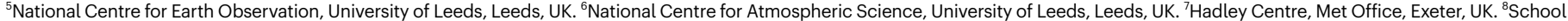
of Chemistry, University of Bristol, Bristol, UK. ${ }^{9}$ Climate Science Centre, CSIRO Oceans and Atmosphere, Aspendale, Victoria, Australia. ${ }^{10}$ Scripps Institution of Oceanography, University of California, La Jolla, CA, USA. " Center for Global Change Science, Massachusetts Institute of Technology, Cambridge, MA, USA. ${ }^{12}$ The Air-Conditioning, Heating, and Refrigeration Institute, Arlington, VA, USA. ${ }^{13}$ Natural Resources Defense Council, Washington, DC, USA. ${ }^{凶}$ e-mail: stephen.a.montzka@noaa.gov 


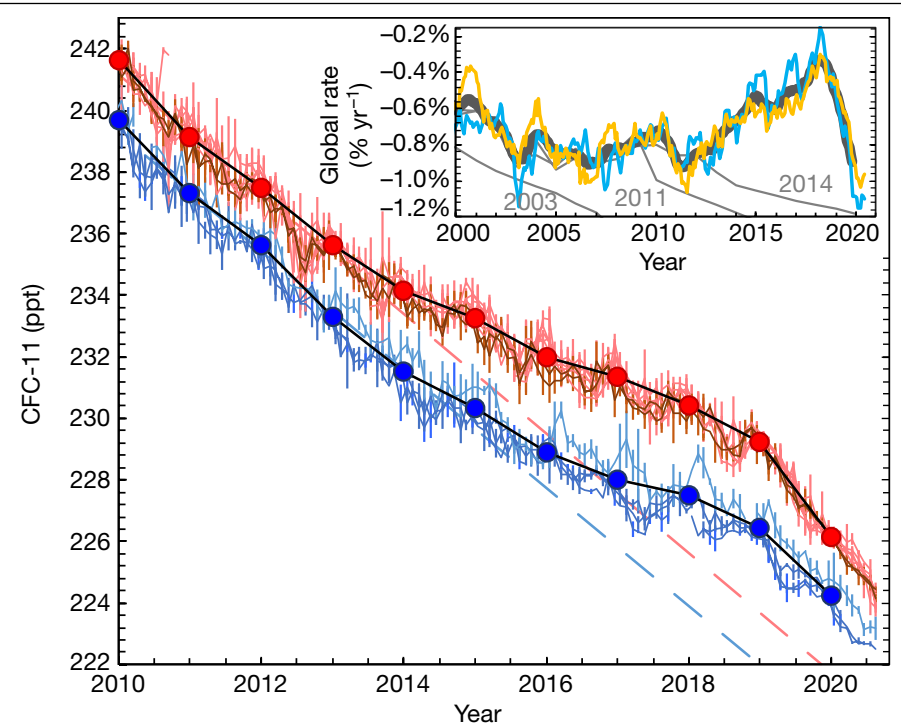

Fig. 1 | Measured atmospheric mole fractions of CFC-11 and global mean rate of change. Monthly mean mole fractions and standard deviations (s.d.) measured at 12 remote sites from NOAA flasks by gas chromatography with mass spectrometry detection (GC-MS) (ref. ; Methods). Corresponding monthly means from the independent AGAGE measurement network ${ }^{27,28}$ (on-site analysis by chromatography coupled with electron capture detection (GC-ECD) at 5 remote sites) appear in Extended Data Fig. 1. Results from individual sites are shown as lines, and vertical bars represent $1 \mathrm{~s}$.d. of all measurements in each month at each site (Southern Hemisphere sites are indicated by blue lines, sites within $0^{\circ}-30^{\circ} \mathrm{N}$ as brown lines, and sites within $30^{\circ}-90^{\circ} \mathrm{N}$ as red lines). Hemispheric 12 -month means centred on 1 January of each year (Northern Hemisphere, red circles; Southern Hemisphere, blue circles; connected by black lines) are derived from results at 12 individual sites (Methods). Dashed lines indicate projections based on fits to hemispheric means during 2002-2012 (Northern Hemisphere, red; Southern Hemisphere, blue). The inset shows the global annual rates of change derived from NOAA (light blue; combined flask and in situ results) and AGAGE (yellow; in situ results) monthly means (as $\ln \left[\operatorname{Jan}_{2020} / \mathrm{Jan}_{2019}\right]$, plotted at 15 January 2020). These network-specific rates are averaged by month and displayed as annually smoothed values (thick grey line). The numbered thin solid lines represent scenario projections in recent World Meteorological Organization Scientific Assessment reports that did not consider any unreported CFC-11 production after 2010 (refs. ${ }^{17,22,23}$, with publication year of each report indicated).

globe enable an early assessment of emission mitigation efforts and provide important constraints on associated future ozone layer damage. The results from two independent global measurement networks show that since late 2018 to early 2019 , after it was reported ${ }^{1}$ that global CFC-11 emissions had unexpectedly increased after 2012, the decline in atmospheric CFC-11 mole fractions measured at all remote sites substantially accelerated (Fig. 1; Extended Data Fig. 1). Compared to the mean decline of $-0.5 \pm 0.1 \% \mathrm{yr}^{-1}$ during 2014-2018, which slowed to $-0.3 \pm 0.1 \% \mathrm{yr}^{-1}$ by $2017-2018$, the global surface mole fraction of CFC-11 decreased at a mean rate of $-0.7 \pm 0.1 \% \mathrm{yr}^{-1}$ between 2018 and 2019. By the end of 2019 and in the first half of 2020 , the global decline rate $\left(-1.0 \pm 0.1 \% \mathrm{yr}^{-1}\right)$ had exceeded that which had been consistently recorded by both networks in any previous year since regular measurements began in the 1970s and was approaching the rate of decline projected in a recent scenario ${ }^{17}$ in which no unreported production had been considered (Fig. 1).

Concurrent with the more rapid decline in global mole fraction, the hemispheric mean (North-South) mole fraction difference decreased from an average of $2.9 \pm 0.1$ parts per trillion (ppt) (National Oceanic and Atmospheric Administration, NOAA) or $2.8 \pm 0.1 \mathrm{ppt}$ (Advanced Global Atmospheric Gas Experiment, AGAGE) during 2014-2017 to $2.1 \mathrm{ppt}$ (NOAA) or $2.0 \mathrm{ppt}$ (AGAGE) in 2019; by the end of 2019 and in early 2020 this difference was similar to values measured in 2008-2012, which was before emissions had increased (Fig. 2). When viewed on a monthly basis, the results suggest that the hemispheric difference began decreasing approximately in mid-2018, although other variables (for example, air transport anomalies during the El NiñoSouthern Oscillation or $\mathrm{ENSO}^{18}$ ) can influence this difference, making the timing of the emission decline difficult to determine precisely (Methods).

Atmospheric measurements at the Mauna Loa Observatory (MLO) suggest that the drop in global CFC-11 emissions stems in part from concurrent emission reductions in eastern Asia. When global emissions of CFC-11 became unexpectedly enhanced (2014-2016), strong correlations emerged in mole fraction variations measured during autumn at MLO between CFC-11 and other anthropogenically emitted gases (for example, $\mathrm{CO}, \mathrm{HCFC}-22\left(\mathrm{CHF}_{2} \mathrm{Cl}\right)$ and $\left.\mathrm{CH}_{2} \mathrm{Cl}_{2}\right)^{1}$. While correlations between $\mathrm{CFC}-11$ and other anthropogenically emitted gases persisted in the autumn of 2017 and 2018, they were no longer present in 2019 (Fig. 3; Extended Data Fig. 2). Air transport analysed with the Numerical Atmospheric dispersion Modelling Environment (NAME) model ${ }^{19}$ indicates that samples collected at MLO were similarly sensitive to emissions from eastern Asia in all these years (Extended Data Fig. 3) and strong correlations among other anthropogenic gases persisted across all years including 2019 (Extended Data Fig. 2).

The accelerated decline in CFC-11 mole fractions at remote sites around the globe, the concurrent decrease in the hemispheric mole fraction difference, and results from MLO are all consistent with substantially reduced global emissions of CFC-11 in 2019. A simple box-model analysis ${ }^{1,3}$ of a combined history of NOAA and AGAGE measurements, assuming no interannual variations in atmospheric transport, provides an initial estimate of global CFC-11 emissions in 2019 of $50( \pm 4, \pm 10) \mathrm{Gg} \mathrm{yr}^{-1}$ (the first uncertainty represents 1 standard deviation (1 s.d.), and the second value is $1 \mathrm{s.d}$. including a CFC-11 lifetime uncertainty; Methods; Fig. 4; Extended Data Fig. 4). This 2019 estimate represents a drop of $21 \pm 6 \mathrm{Gg} \mathrm{yr}^{-1}(30 \pm 8 \%)$ when compared to mean emissions during 2014-2018 and is comparable to or smaller than emissions before 2013, when the anomalous emission increase first began (2008-2012 mean: $\left.57( \pm 3, \pm 10) \mathrm{Gg} \mathrm{yr}^{-1}\right)$.

This initial emission estimate for 2019 ignores variability in atmospheric dynamics (transport and mixing) that can affect CFC-11 loss, influence measured mole fractions, and bias global emission estimates derived from global-scale measurements, especially over periods of up to $3-5$ years ${ }^{1,20}$. To account for these biases, we performed forward simulations in two three-dimensional (3D) models constrained by observed meteorology and with smoothly varying emission histories as input ${ }^{20}$ (Methods). Perturbations in surface mole fractions simulated by the 3D models were used to estimate bias corrections on global emissions (Methods; Extended Data Figs. 5, 6). Similar bias corrections were derived from both 3D models in most years despite different representations of global winds.

The bias-corrected global CFC-11 emission histories confirm a sharp decline in CFC-11 emissions after 2018 to a value in 2019 of $52( \pm 5, \pm 10) \mathrm{Gg} \mathrm{yr}^{-1}$, which is considerably smaller than emissions in any year since 2013 and is comparable to the 2008-2012 mean of $56( \pm 5, \pm 10) \mathrm{Gg} \mathrm{yr}^{-1}$ (Fig. 4). The 2019 global CFC-11 emission is $17 \pm 7 \mathrm{Gg} \mathrm{yr}^{-1}(25 \pm 10 \%)$ lower than the 2014-2018 mean value or $18 \pm 6 \mathrm{Gg} \mathrm{yr}^{-1}(26 \pm 9 \%)$ lower than the 2018 value alone (Fig. 4). This drop is similar to the global emission increase of $13 \pm 7 \mathrm{Gg} \mathrm{yr}^{-1}$ from the 2008-2012 period (mean of $56( \pm 5, \pm 10) \mathrm{Gg} \mathrm{yr}^{-1}$ ) to the 2014-2018 period (mean of $\left.69( \pm 5, \pm 10) \mathrm{Gg} \mathrm{yr}^{-1}\right)$.

Although the use of 3D models and reanalysed wind fields to accurately account for the influence of variable dynamics on trace gas mole fractions remains an area of active research ${ }^{1,21}$, the resulting global emission histories show features not apparent in uncorrected estimates (Fig. 4). For example, the bias-corrected emissions show smaller inter-annual changes, particularly after 2010 , qualitatively consistent 

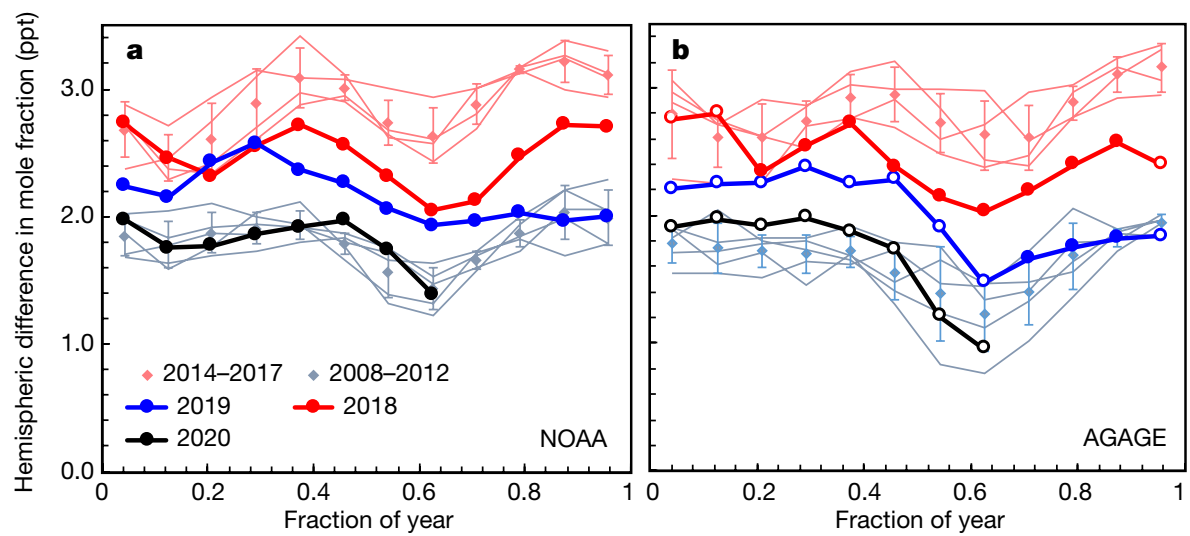

Fig. 2 | Hemispheric differences in CFC-11 mole fraction. Hemispheric differences during recent years estimated by independent measurement networks (a, NOAA; b, AGAGE) are plotted as a function of fraction of year; points delineate monthly mean hemispheric differences and colours indicate different years. Hemispheric differences measured during 2008-2012 (each year represented by a grey line; grey points with errors indicate the monthly 5-yr means and 1s.d.) are lower than those measured during 2014-2017 (each year represented by a light red line; light red points with errors indicate the

with emissions being dominated by a large bank, although this change is less prominent in results for years before 2010. The bias-corrected emission histories also show a notable decline $\left(-2 \pm 0.5 \% \mathrm{yr}^{-1}\right)$ during 2002-2012 that is not present in uncorrected estimates ${ }^{1}$ but is more consistent with expectations of decreasing emissions from banks ${ }^{4,15-17,22,23}$. This difference stems in part from a known perturbation in stratospheric dynamics during 2000-2006 (ref. ${ }^{24}$; Extended Data Fig. 6). Furthermore, the corrected emissions histories suggest that both the sharp emission increase in 2014 and mean emissions during 2014-2016 were augmented in part by dynamics, although, for the latter, by a smaller amount than was estimated previously ${ }^{1}$ (see Methods).

While the results from MLO reveal that emission reductions in eastern Asia contributed to the global decline, accurate mapping or quantification of emission changes in eastern Asia is prevented by the large distance between these locations. In the accompanying paper $^{25}$, an

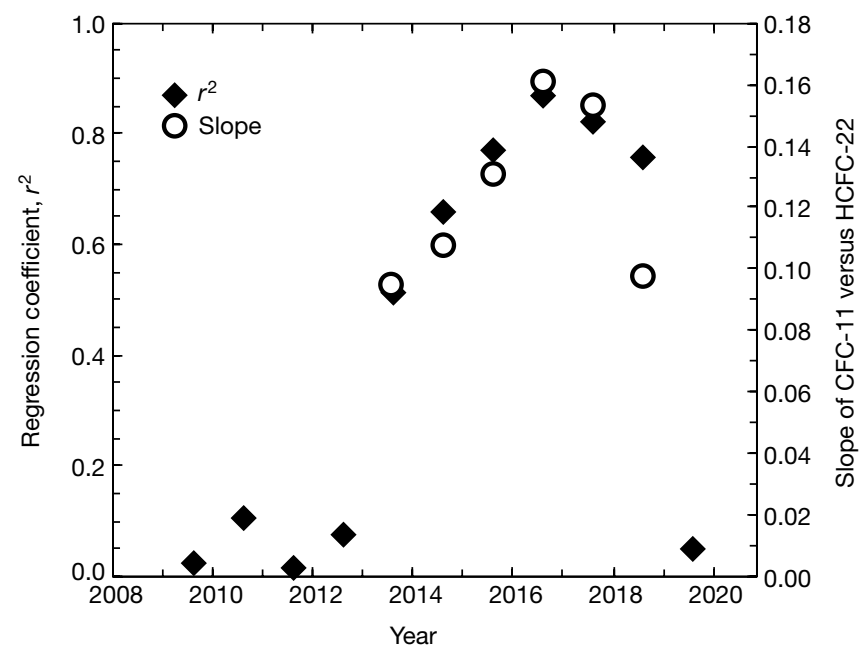

Fig. 3 | Co-variations observed between mole fractions of CFC-11 and HCFC-22 at MLO. Linear regression coefficients ( $r^{2}$; diamonds, left axis) and slopes (circles, right axis) derived annually from measured mole fractions in all samples collected during autumn of each year (see Extended Data Fig. 2). Linear regression slopes are shown only for years in which significant $(P<0.05$ and $r^{2}>\sim 0.25$ ) correlations were measured (2013 through 2018). Tick marks on the $x$ axis refer to 1 January of the indicated year. monthly 5-yr means and 1s.d.). Results from 2018 (red), 2019 (blue) and 2020 (black) show a transition from larger to smaller Northern HemisphereSouthern Hemisphere differences that become notable after mid-2018. Similar changes through these years are apparent in results from both measurement networks despite differences in measurement locations and techniques (Methods). Months in which results from only 4 of 5 AGAGE stations are available during 2018-2020 are indicated with white-filled circles.

inverse analysis of CFC-11 concentration enhancements at two eastern Asian sites reveals substantial emission reductions in eastern China after 2017. When considered relative to the global CFC-11 emissions reported here, those regional influences account for $60 \pm 30 \%$ of the global emission decline in 2019 relative to the 2014-2017 mean. The result suggests that other regions also contributed to the post-2017 reduction in excess global emissions (Extended Data Fig. 7).

The rate of decline in the global mole fraction, the hemispheric mole fraction difference, and global and eastern China emissions ${ }^{25}$ all returned to pre-2013 values before the end of 2019, and so were not associated with the SARS-CoV-2 outbreak, which caused reduced economic activity beginning in late January of 2020 (ref. ${ }^{26}$ ). Instead, they probably stem from increased enforcement actions taken after 2017 in China and elsewhere.

Our understanding of banks suggests that global emissions would have declined after 2010 without renewed production ${ }^{4,15-17,22,23}$. Hence, the impact of renewed production on the ozone layer is best estimated by comparing observationally derived emissions to their expected changes. Expectations extrapolated from past emission trends (for example, 2002-2012) or that imply minimal changes in fractional emission rates from banks after 2010 suggest a mean excess global emission during 2014-2018 of 17-37 $\mathrm{Gg} \mathrm{yr}^{-1}$ and excess global emission in 2019 of 2-24 Gg yr ${ }^{-1}$ (Methods; Extended Data Fig. 7). However, substantially larger excess emissions are implied by expectations from an inventory model ${ }^{4}$ in which the overall bank release fraction and expected emissions decline by a factor of 2 after reported production was to have ceased (2010). The large drop in expected emissions from banks in the inventory model stems from assumptions related to end-of-life practices for CFC-11, particularly in chillers and foams. Until more is known about how these practices might have changed during these years, estimates of excess emission amounts in 2019 will contain substantial uncertainty.

Future CFC-11 emissions will be enhanced above expectations by additions to banks from unreported production, probably as foams ${ }^{4}$. Based on industry estimates of possible blowing agent losses during production (4-10\%) and during the foam blowing process (17-50\% depending on foam type and formulation), global unreported production of 25-100 $\mathrm{Gg} \mathrm{yr}^{-1}$ is implied, on average, between 2013 and 2018, based on excess emission magnitudes considered here (Methods; ref. ${ }^{4}$; Extended Data Fig. 8). Although substantially larger amounts of production can be derived (up to $160 \mathrm{Gg} \mathrm{yr}^{-1}$; Extended Data Fig. 8), 


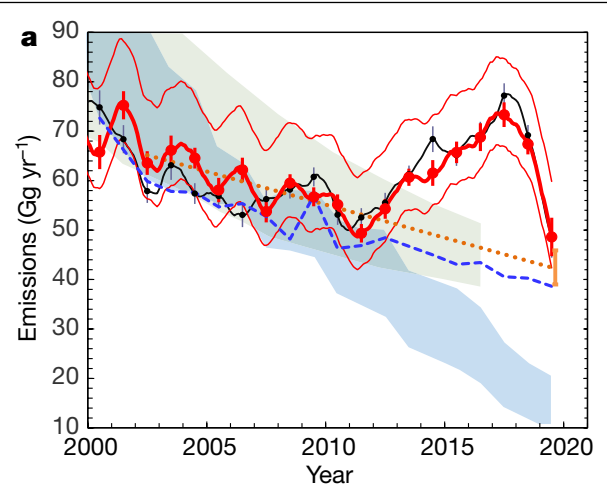

Fig. 4 | Observation-based global CFC-11 emissions versus expected changes. a, Global CFC-11 emissions derived from a combined NOAA and AGAGE mole fraction history and a 3-box model with constant dynamics (air mixing times between boxes; black points and lines) and with consideration of time-varying dynamics estimated from the 3D model Whole Atmosphere Community Climate Model ${ }^{33,34}$ (WACCM) (red points and thick red lines) (points represent calendar year means) (see Methods). b, Same as a, but with the influence of time-varying dynamics estimated using the 3D model TOMCAT. Uncertainties ( 1 s.d.) on annual values were derived considering only measured atmospheric variability and network representation errors (Methods). Also shown are multiple estimates of expected emissions in the absence of unreported production after 2010. These expectations are from:

they may be less likely given that reported production in the Montreal Protocol's Article 5 Parties (developing countries) peaked in the late $1990 \mathrm{~s}$ at $<50 \mathrm{Gg} \mathrm{yr}^{-1}$ and other foam-blowing agents are likely to have been adopted for some types of closed-cell foam ${ }^{4}$.

The analysis discussed above implies that foam banks of CFC-11 at the beginning of 2020 have been augmented by $90-725 \mathrm{Gg}$ as a result of unreported CFC-11 production in recent years through 2019 (Extended Data Fig. 8). For comparison, an analysis of regional measurements suggests an increase in CFC-11-containing banks in eastern China of up to $112 \mathrm{Gg}$ in 2019 (ref. ${ }^{25}$ ). Although the size of the existing global foam banks is uncertain, relative to a bank of $1,300-1,600 \mathrm{Gg}$ (refs. ${ }^{4,15}$ ), the additions derived here would suggest a $6-45 \%$ increase in the global 2020 bank and in cumulative future emissions.

If the reductions in global emissions and implied production noted here are sustained, future enhancements in atmospheric chlorine from unreported CFC-11 production in recent years through 2019 will be limited to $<60 \mathrm{ppt}$ ( or $<2.5 \%$ of total atmospheric chlorine from other gases; Extended Data Fig. 8). This would represent a substantially smaller impact on ozone than the $300 \mathrm{ppt}$ of chlorine enhancement derived for 2100 if ongoing CFC-11 production had sustained future emission at its 2002-2016 mean rate $\mathrm{e}^{16}$.

Our results show that the rapid mitigation efforts encouraged by the Parties to the Montreal Protocol and adopted by countries in eastern Asia and worldwide ${ }^{5,25}$ enabled a dramatic reduction in global CFC-11 emissions by 2019 to pre-2013 values. Although emissions in 2019 may still be above expectations, the downward trajectory of global CFC-11 emissions has been restored. Provided these mitigation efforts are sustained, the substantial delays in ozone layer recovery projected from recent CFC-11 trends that were inconsistent with Montreal Protocol controls ${ }^{8,11,12,16}$ will have been avoided.

\section{Online content}

Any methods, additional references, Nature Research reporting summaries, source data, extended data, supplementary information, acknowledgements, peer review information; details of author contributions and competing interests; and statements of data and code availability are available at https://doi.org/10.1038/s41586-021-03260-5.

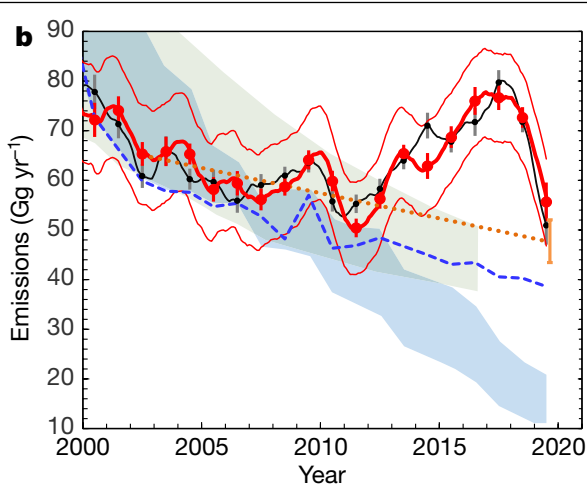

(1) an extrapolation of the observationally derived emissions decline during 2002 to 2012 (orange dotted line, 1 s.d. uncertainty on 2019.5 value is shown), (2) results from a Bayesian probabilistic model analysis of banks and emissions that incorporates observational and inventory data ${ }^{15}$ (grey-green shaded area), (3) multiple representations of TEAP's inventory model ${ }^{4}$ (blue-shaded region), and (4) a modification of TEAP's 'most likely' scenario (blue-dashed line; TEAP*, Methods). Observationally derived emissions in the two panels are offset slightly because they were derived with mean CFC-11 lifetimes inherent to the 3D models: $56 \mathrm{yr}$ for WACCM and $54 \mathrm{yr}$ for TOMCAT. The influence of uncertainty in the CFC-11 lifetime on observationally derived emissions was calculated for lifetimes of $50 \mathrm{yr}$ and $60 \mathrm{yr}$ (thin red lines; ref. ${ }^{29}$; Methods).
1. Montzka, S. A. et al. An unexpected and persistent increase in emissions of ozone-depleting CFC-11. Nature 557, 413-417 (2018).

2. Engel, A. et al. in Scientific Assessment of Ozone Depletion: 2018. Global Ozone Research and Monitoring Project. Report No. 58, Chapter 1, 1-87 (World Meteorological Organization, 2018).

3. Rigby, M. et al. Increase in CFC-11 emissions from eastern China based on atmospheric observations. Nature 569, 546-550 (2019).

4. United Nations Environmental Programme (UNEP)/Technology and Environmental Assessment (TEAP). Volume 3:Decision XXX/3 TEAP Task Force Report On Unexpected Emissions Of Trichlorofluoromethane (CFC-11). https://ozone.unep.org/sites/default/ files/2020-07/TEAP_Task_Force_Dec_XXX-3_on_Unexpected_CFC-11_Emissions_May_2019. pdf (eds Pons, J., Tope, H. \& Walter-Terrinoni, H.) Vol. 3 (UNEP/TEAP, 2019).

5. United Nations Environmental Programme (UNEP). Report of The Thirtieth Meeting of the Parties to the Montreal Protocol on Substances that Deplete the Ozone Layer. Report number UNEP/OzL.Pro.30/11, https://ozone.unep.org/system/files/documents/MOP-3011E.pdf (UNEP, 2019).

6. Harris, N., Montzka, S. A. \& Newman, P. A. The international symposium on the unexpected increase in emissions of ozone-depleting CFC-11. SPARC 53, 9-18 (2019); https://www.sparc-climate.org/wp-content/uploads/sites/5/2019/07/SPARCnewsletter July2019_WEB.pdf.

7. Environmental Investigation Agency (EIA). BLOWING IT: Illegal Production and Use of Banned CFC-11 in China's Foam-Blowing Industry. https://content.eia-global.org/posts/ documents/O00/000/761/original/Blowing-It_CFC11_Report_EIA.pdf?1531089183 (EIA, 2018).

8. Dhomse, S. S. et al. Delay in recovery of the Antarctic ozone hole from unexpected CFC-11 emissions. Nat. Commun. 10, 5781 (2019).

9. Adcock, K. E. et al. Investigation of east Asian emissions of CFC-11 using atmospheric observations in Taiwan. Environ. Sci. Technol. 54, 3814-3822 (2020).

10. Lin, Y. et al. Observations of high levels of ozone-depleting CFC-11 at a remote mountain-top site in southern China. Environ. Sci. Technol. Lett. 6, 114-118 (2019).

11. Fleming, E. L., Newman, P. A., Liang, Q. \& Daniel, J. S. The impact of continuing CFC-11 emissions on stratospheric ozone. J. Geophys. Res. 125, e2019JD031849 (2020).

12. Dameris, M., Jöckel, P. \& Nützel, M. Possible implications of enhanced chlorofluorocarbon-11 concentrations on ozone. Atmos. Chem. Phys. 19, 13759-13771 (2019).

13. United Nations Environmental Programme (UNEP). Executive Committee of the Multilateral Fund for the Implementation of the Montreal Protocol, Eighty-third Meeting. Addendum: Reports On Projects With Specific Reporting Requirements. Report number UNEP/OzL.Pro/ExCom/83/11/Add.1, http://multilateralfund.org/83/English/1/8311a1.pdf (UNEP, 2019).

14. United Nations Environmental Programme (UNEP). Report of China on progress made in the monitoring and management system on ozone-depleting substances. In Thirty-First Meeting of the Parties to the Montreal Protocol on Substances that Deplete the Ozone Layer UNEP/OzL.Pro.31/INF/9 (UNEP, 2019).

15. Lickley, M. et al. Quantifying contributions of chlorofluorocarbon banks to emissions and impacts on the ozone layer and climate. Nat. Commun. 11, 1380 (2020).

16. Carpenter, L. J. et al. in Scientific Assessment of Ozone Depletion: 2018. Global Ozone Research and Monitoring Project. Report number 58, Ch. 6, 1-69 (World Meteorological Organization, 2018).

17. Harris, N. R. P. et al. in Scientific Assessment of Ozone Depletion: 2014. Global Ozone Research and Monitoring Project. Report number 55, Chapter 5, 1-58 (World Meteorological Organization, 2014). 


\section{Article}

18. Chen, Y. H. \& Prinn, R. G. Atmospheric modeling of high frequency methane observations: importance of inter-annually varying transport. J. Geophys. Res. 110, D10303 (2005)

19. Jones, A. R., Thomson, D. J., Hort, M. \& Devenish, B. in Air Pollution Modeling And Its Application XVII (eds Borrego, C. \& Norman, A.-L.) Ch. 62, 580-589 (Springer, 2007)

20. Ray, E. et al. The influence of the stratospheric quasi-biennial oscillation on trace gas levels at the Earth's surface. National Geographic 13, 22-27 (2020).

21. Laube, C. et al. Investigating stratospheric changes between 2009 and 2018 with halogenated trace gas data from aircraft, AirCores, and a global model focusing on CFC-11. Atmos. Chem. Phys. 20, 9771-9782 (2020).

22. Daniel, J. et al. in Scientific Assessment of Ozone Depletion: 2010. Global Ozone Research and Monitoring Project. Report number 52, Ch. 5, 1-56 (World Meteorological Organization, 2011)

23. Montzka, S. A. et al. in Scientific Assessment of Ozone Depletion: 2002. Global Ozone Research and Monitoring Project. Report number 47, Ch. 1, 1-83 (World Meteorological Organization, 2003)

24. Randel, W. J., Wu, F., Vömel, H., Nedoluha, G. E. \& Forster, P. Decreases in stratospheric water vapor after 2001: links to changes in the tropical tropopause and the Brewer-Dobson circulation. J. Geophys. Res. 111, D12312 (2006).
25. Park, S. et al. A decline in emissions of CFC-11 and related chemicals from eastern China. Nature https://doi.org/10.1038/s41586-021-03277-w (2021).

26. Liu, F. et al. Abrupt decline in tropospheric nitrogen dioxide over China after the outbreak of COVID-19. Sci. Adv. 6, eabc2992 (2020).

27. Prinn, R. G. et al. A history of chemically and radiatively important gases in air deduced from ALE/GAGE/AGAGE. J. Geophys. Res. 105, 17751-17792 (2000).

28. Prinn, R. G. et al. History of chemically and radiatively important atmospheric gases from the Advanced Global Atmospheric Gases Experiment (AGAGE). Earth Syst. Sci. Data 10 985-1018 (2018).

29. Ko, M. K. W., Newman, P. A., Reimann, S. \& Strahan, S. E. in Lifetimes of Stratospheric Ozone-Depleting Substances, Their Replacements, and Related Species. Stratospheric Processes And their Role in Climate (eds Ko, M. et al.) SPARC Report No. 6 (SPARC, 2013).

Publisher's note Springer Nature remains neutral with regard to jurisdictional claims in published maps and institutional affiliations.

(c) The Author(s), under exclusive licence to Springer Nature Limited 2021 


\section{Methods}

\section{Observations}

Ambient air measurements of CFCs were obtained by two independent global networks, the NOAA and the AGAGE, at a total of thirteen unique surface sites throughout the globe using multiple techniques ${ }^{1,3,27,28}$ (Extended Data Table 1). Multiple approaches are taken to reduce any local emissive influences on estimates of background atmospheric CFC mole fractions and their change over time. These approaches include considering monthly medians instead of means for on-site results at remote NOAA sites, a statistical filter to derive pollution-free monthly means ${ }^{30}$, visual inspection, consideration of back-trajectories, and only using flask results obtained when air was from a pre-specified clean air sector. Variability (1 s.d.) since 2010 in measured monthly mean mole fractions averaged $0.2-0.5 \mathrm{ppt}$ for NOAA GCMS flask analysis and $0.2-0.4 \mathrm{ppt}$ for AGAGE in situ electron capture detection measurements, depending on site.

\section{Hemispheric mole fraction differences}

Hemispheric concentration differences reflect hemispheric asymmetries in emission magnitudes and loss, and these asymmetries are modulated by interhemispheric transport. For long-lived trace gases with only anthropogenic sources, such as the CFCs, hemispheric concentration differences are primarily determined by emission magnitudes $^{31}$. For example, ENSO can affect CFC-11 mole fraction gradients across the Equator in the tropics. After removing the long-term trend (using a quadratic polynomial fit), seasonal cycle and quasi-biennial oscillation cycle in this gradient measured at Barbados $\left(13^{\circ} \mathrm{N}\right)$ and American Samoa ( $14^{\circ} \mathrm{S}$ ) (AGAGE data), the correlation between the residuals and the MEI.v2 ENSO index is strong (Pearson's correlation coefficient $r=0.41$ for $1995-2020$ and 0.51 for 2010-2020), and the range of the residuals is $\pm 0.5 \mathrm{ppt}$. ENSO influences on hemispheric differences are reduced, by comparison, when hemispheric mean concentrations are considered, and they were not removed from results presented in Fig. 2.

\section{MLO sensitivity to east Asian emissions}

The NAME, a Lagrangian atmospheric transport model developed by the UK Met Office ${ }^{19}$, was used to estimate the surface sensitivity of concentrations measured in flasks collected at MLO to emissions from different regions in eastern Asia (Extended Data Fig. 3). NAME is driven by meteorology from the UK Met Office's operational weather forecasting model (horizontal resolution in longitude $0.141^{\circ}$ and in latitude $0.094^{\circ}$, with 60 vertical levels in the lowest $30 \mathrm{~km}$ of the atmosphere). NAME was run backwards in time, releasing $1 \mathrm{~g} \mathrm{~h}^{-1}$ of material distributed over 100,000 air parcels at 3,433 $\mathrm{m}$ above sea level. These were followed for a maximum of 30 days or until they left a domain covering $90^{\circ} \mathrm{E}$ to $255^{\circ} \mathrm{E}$ longitude and $-10^{\circ}$ to $69^{\circ}$ latitude. A 30-day time-integrated air concentration $\left(\mathrm{g} \mathrm{s} \mathrm{m}^{-3}\right)$ was output from NAME at a resolution of $0.352^{\circ}$ longitude by $0.234^{\circ}$ latitude within $2 \mathrm{~km}$ of the ground.

\section{Observationally derived global emissions}

Global CFC emissions were estimated with 3-box and 12-box models to yield tropospheric mole fractions consistent with surface data using established methodologies ${ }^{1,3}$ with some modifications to enable the consideration of NOAA and AGAGE data together (see below). The loss rate constant in the 3-box-modelled stratosphere was adjusted to provide a steady-state lifetime matching the mean CFC-11 lifetime diagnosed in the 3D models ( $56 \mathrm{yr}$ for WACCM and $54 \mathrm{yr}$ for TOMCAT). Additional estimates were made with lifetimes of $50 \mathrm{yr}$ and $60 \mathrm{yr}$ based on the 1 s.d. range of lifetimes diagnosed in two-dimensional and 3D models for recent years ${ }^{29}$. The 12-box model consists of three vertical levels, separated at $500 \mathrm{hPa}$ and $200 \mathrm{hPa}$, and four equal mass latitudinal bands, with divisions at the Equator and $30^{\circ}$ North and South.
The loss rate in the stratospheric boxes was adjusted until the global CFC-11 lifetime was equal to $52 \mathrm{yr}$ (for NOAA- and AGAGE-specific results appearing in Extended Data Fig. 4a, b; ref. ${ }^{29}$ ).

Uncertainties on annual mole fractions and emissions were estimated with a bootstrap technique using replacement ${ }^{32}$ and represent the influences of measurement repeatability, atmospheric variability, calibration differences between NOAA and AGAGE, and representation errors associated with the finite number of sampling locations within each semi-hemisphere (Extended Data Table 1). This analysis was performed on NOAA and AGAGE data considered separately (Extended Data Fig. 4) or together (as in Fig. 4). Start-of-year mole fractions were derived from 480 representations of semi-hemispheric means as measured by either NOAA, AGAGE or a combination of results from both networks that were averaged to a global mean. Semi-hemispheric monthly means derived from NOAA data were derived from a random selection of sites within each semi-hemisphere. In each network representation, random noise was added to monthly site means by an amount equivalent to the measured monthly standard deviation. For data from the American Samoa station $(\mathrm{SMO})\left(0^{\circ}-30^{\circ} \mathrm{S}\right)$, however, measured monthly standard deviations were multiplied by a factor of 2 to account for this semi-hemisphere being characterized with results from only one site. With this procedure, uncertainties on annual mean mole fractions centred on 1 January of each year were derived, thereby enabling an estimate of uncertainty on calendar year emissions (as 1 s.d.). The first uncertainty quoted (1 s.d.) on all bias-corrected emissions includes an additional term related to uncertainty in the bias correction (Extended Data Fig. 6). Emissions and bias corrections on emissions were also derived for annual mean mole fractions centred on other months of the year, and these appear as the smoothly varying lines in Fig. 4 and Extended Data Figs. 4, 6.

The second uncertainty listed on annual or multi-year emission estimates is a total uncertainty that includes uncertainty in the global lifetime of CFC-11 (see Fig. 4 ; ref. ${ }^{29}$ ). Note that changes in emissions are not quoted with a second uncertainty because they are insensitive to lifetime when derived over periods that are short relative to the CFC-11 lifetime.

\section{Estimating dynamical influences}

Three-dimensional model simulations were used to estimate the influence of dynamics-induced variability on CFC-11 mole fractions and derived emissions. CFC-11 mole fraction histories were calculated in forward simulations in the WACCM ${ }^{33,34}$ and the offline chemical transport model TOMCAT ${ }^{35,36}$. In both 3D models, global mole fractions and distributions of CFC-11 were initialized in the year 1980. The WACCM model was run with interactive chemistry in the specified dynamics configuration at a resolution of $1.9^{\circ}$ latitude $\times 2.5^{\circ}$ longitude horizontal with 88 vertical levels from Earth's surface to $6 \times 10^{-6} \mathrm{hPa}$. Horizontal winds and temperatures were nudged to specified dynamics derived from the Modern Era Retrospective-analysis for Research and Applications (MERRA2) ${ }^{33,34}$. The TOMCAT simulation parameterized the atmospheric loss of CFC-11 tracers using calculated photolysis rates and a repeating year of archived monthly zonal mean distributions of electronically excited oxygen atoms $\left(\mathrm{O}\left({ }^{1} \mathrm{D}\right)\right)$ from a previous full chemistry simulation ${ }^{8}$. The model was run at a resolution of $2.8^{\circ} \times 2.8^{\circ}$ with 60 levels from the surface to $0.1 \mathrm{hPa}$ and was forced using the ERA-5 reanalyses (horizontal winds, temperatures) ${ }^{37}$ from the European Centre for Medium-Range Weather Forecasts (ECMWF). In TOMCAT, the large-scale vertical transport was diagnosed from the divergence of the horizontal winds.

The method for deriving dynamics-induced emission biases was performed in a manner similar to Ray et al. ${ }^{20}$ in which a smoothly varying emission history was used as input to forward runs of the 3D models. Our analysis, however, includes all simulated variability, not just related to the quasi-biennial oscillation as in ref. ${ }^{20}$. The smoothed 
input global emissions were derived from the 3-box model analysis of surface measurements (a smoothed version of black lines in Fig. 4) and were distributed as follows: $0 \%$ from $90^{\circ} \mathrm{N}$ to $60^{\circ} \mathrm{N}, 5 \%$ from $60^{\circ} \mathrm{N}-50^{\circ} \mathrm{N}, 80 \%$ from $50^{\circ} \mathrm{N}-25^{\circ} \mathrm{N}, 12 \%$ from $25^{\circ} \mathrm{N}-10^{\circ} \mathrm{S}, 3 \%$ from $10^{\circ} \mathrm{S}-40^{\circ} \mathrm{S}, 0 \%$ from $40^{\circ} \mathrm{S}-90^{\circ} \mathrm{S}$ (equivalent to $90 \%$ of emission north of $10^{\circ} \mathrm{N}$ ). Mole fractions simulated from the 3D model runs were extracted from the grid cells corresponding to the NOAA and AGAGE measurement locations and were used to derive hemispheric and global mean mole fractions.

Surface mole fractions simulated in the 3D model have an added variability that arises from dynamics that is of order of $\pm 0.2 \% \mathrm{yr}^{-1}$ in annual rates of change on a 1 to 3 -yr timeframe (Extended Data Fig. 5). Despite using different models and different representations of meteorology, the main features of the simulated variability in mole fraction rates are apparent in both model results and, notably, are also present in measured hemispheric means, particularly the peaks in early 2015 and 2018.

The mole fractions simulated in the 3D forward runs were used to derive a second global emission history using the 3-box model and the same methodologies applied to measurement data. Differences between the smoothed input and second emission histories were taken to represent emission biases arising from the influence of dynamical variability on CFC-11 atmospheric mole fractions (Extended Data Fig. 6). These biases (calculated on a monthly basis) were subtracted from the 3-box model emission history derived directly from observations to provide a best-estimate emission history for CFC-11 (Fig. 4 and Extended Data Fig. 4).

\section{Expected emissions after 2012}

Without post 2010 production, CFC-11 emissions were expected to slowly decline thereafter as reservoirs of CFC-11 (banks), primarily in foam, but also in industrial process refrigeration and comfort cooling for commercial buildings (chillers), diminished from the CFC-11 escaping to the atmosphere ${ }^{4,15-17,22,23}$. To better quantify the effect of renewed CFC-11 production on future ozone depletion, we examined differences between observed emissions and those expected in the absence of renewed production ('excess emission').

We considered multiple methods for estimating expected global CFC-11 emissions in the absence of renewed unreported production. Emission expectations were derived for 2013-2019 from a linear fit to the observationally derived bias-corrected emissions during 2002 to 2012 (orange-dotted line, Fig. 4). This approach projects a global emission in 2019 of $42 \pm 3 \mathrm{Gg} \mathrm{yr}^{-1}$ (WACCM/MERRA2 dynamical corrections) or $48 \pm 4 \mathrm{Gg} \mathrm{yr}^{-1}$ (TOMCAT/ECMWF dynamical corrections) and bank release fractions during 2010-2019 that remain constant at about 3\% $\mathrm{yr}^{-1}$. The consistency in results for fits over different ranges of years (2002-2012,2003-2012, and so on, through 2008-2012) suggests no appreciable influence of small amounts of CFC-11 production reported during 2002-2010 (110 Gg) (ref. $\left.{ }^{1}\right)$.

We also consider expected CFC-11 emissions derived through 2016 with a Bayesian probabilistic model in the absence of post-2010 production ${ }^{15}$. The model includes a wide range of observation-based and inventory-based information to derive posterior estimates of banks magnitudes and emissions through 2016 (Fig. 4). In part because this analysis is constrained by observations, it yields similar emissions and emission trends to those suggested by observations during 2002-2012; it also suggests post-2012 emissions that are similar to those derived from the observation-based extrapolated fit and only small changes in bank release fractions in recent years (median estimate drops from $3.0 \% \mathrm{yr}^{-1}$ in 2006 to $2.7 \% \mathrm{yr}^{-1}$ by 2016).

Expected emissions are taken from the Montreal Protocol's Technology and Environmental Assessment (TEAP) inventory model ${ }^{4}$, which provides a CFC-11 emission history starting in the 1930 s based on reported production data, breakdown of use in multiple applications such as chillers, foam manufacturing, as an aerosol propellant, and as a solvent and more than 20 parameters representing the lifetime of products, and time-dependent emission rates associated with manufacturing, installation, use, decommissioning (transfer to landfill), and at end of life. Values for these parameters are based on existing literature, historical data, and input from industry experts associated with TEAP and its reports. The original TEAP model considered different values for some parameters in four different scenarios, thus providing a range of expected emissions that decrease substantially from 2010 to 2020 (Fig. 4, blue-shaded region). Here, we limit our attention to the 'most likely' scenario originally developed ${ }^{4}$ by TEAP, which falls within the range of the other scenarios in most years, as it was developed with parameter values considered to be the most likely. This scenario results in a substantial drop in fractional bank losses (3.6-1.4\% $\left.\mathrm{yr}^{-1}\right)$ and, therefore, total emissions during 2010-2020 owing to end-of-life assumptions made for CFC-11-containing products and the fate of that CFC-11 as those products are retired. In this scenario, enhanced emissions related to production, active use, and the transition of chillers to landfill become negligible shortly after 2010 and overall emissions in subsequent years are sustained only by the small release rates from foams in situ and foams in a landfill (both are $\leq 1.5 \% \mathrm{yr}^{-1}$ ), or related to transitioning foam-containing products to a landfill (for example, building decommissioning, during which only a small fraction of the CFC escapes ${ }^{4}$ ). As a result, the 2010-2020 emission decline in the 'most likely' TEAP scenario depends in large part on the accuracy of assumptions of end-of-life treatment and mean in-use lifetime of chillers, parameters whose values were not explicitly explored in the TEAP report ${ }^{4}$.

As a result of this sensitivity, we considered an alternative scenario $\left(\right.$ TEAP $\left.^{*}\right)$ that enabled continued emissions from chillers past 2012, since CFC-11 containing chillers continue to be used throughout the world ${ }^{4}$. Whereas there are many factors affecting emissions from chillers (for example, recapture or venting of refrigerant during recharge and at end of life that probably vary), the lack of historical detailed information on these practices prevents their explicit modelling. Instead, we allowed for sustained emissions from chillers by assuming a longer in-use lifetime for CFC chillers ( $35 \mathrm{yr}$ versus $25 \mathrm{yr}$ ) and a $10 \%$ increase in pre-2010 reported production for all applications (as explored elsewhere ${ }^{4,15}$ ) (TEAP*; Fig. 4). Longer mean chiller lifetimes may be likely especially now, since commercial chillers are currently professionally serviced and maintained through well established service contracts. The high cost of replacement can lead to slow decommissioning rates, potentially only after a catastrophic failure. Furthermore, chiller lifetimes in Brazil are estimated to be 30 years and, in India, 40 years ${ }^{38}$. In addition, the World Bank has forecast that "the demand for recycled CFCs for servicing large capacity chillers will continue till 2027" (ref. ${ }^{38}$ ), which is more than a decade after the year (2012) implied by a 25-yr chiller lifetime. The effect of this simple adjustment to TEAP's 'most likely' model produces an overall bank release fraction that remains close to $3 \% \mathrm{yr}^{-1}$ from 2000 to 2020 , and it provides emission expectations after 2010 that are similar to those derived by Lickley et al. ${ }^{15}$ and projected from the extrapolated linear fit to observationally derived emissions, given a CFC-11 lifetime of $55-60 \mathrm{yr}$.

\section{Estimating excess global emissions}

Excess global emissions (emissions above expectations considering only reported production) were derived as the difference between observationally based estimates and expected emissions estimated using methods discussed above. Excess emissions declined notably from 2018 to 2019, but suggest that emissions in 2019 may remain elevated above expectations (Extended Data Fig. 7) by different amounts. Relative to the extrapolation of derived emissions during 2002-2012, the estimated excess emission in 2019 is $7 \pm 6 \mathrm{Gg} \mathrm{yr}^{-1}$ and is insensitive to the CFC-11 lifetime, and the average over 2014-2018 is $21 \pm 3 \mathrm{Gg} \mathrm{yr}^{-1}$. Relative to TEAP* expectations, excess 
emissions in 2019 are 5-24 $\mathrm{Gg} \mathrm{yr}^{-1}$, and the average during 2014-2018 is $18-37 \mathrm{Gg} \mathrm{yr}^{-1}$. Based on the consistency among excess emissions derived from these expectations, which are also consistent with those derived from Lickley et al. ${ }^{15}$ during overlapping years, we estimate excess CFC-11 emission in 2019 of 2-24 Gg yr ${ }^{-1}$. Larger excess emissions (24-46 $\mathrm{Gg} \mathrm{yr}^{-1}$ ) are suggested for 2019 and earlier years from TEAP's 'most likely' scenario and CFC-11 lifetimes at the shorter end of the range explored here (50-60 yr), but we consider these magnitudes less likely given evidence suggesting that chiller emissions are probably continuing and that most atmospheric models suggest a mean CFC-11 lifetime of between 55 and $60 \mathrm{yr}$ $\left(\right.$ ref. $\left.{ }^{29}\right)$. Such large increases also seem unlikely because they would have to come from regions other than those dominating past CFC use (the USA and the European Union), given the observational evidence suggesting no recent increases from these regions ${ }^{1,3}$ and a near complete decline by 2019 in excess CFC-11 emissions from eastern China $^{25}$ (Extended Data Fig. 7).

Continued unexpected emissions for CFC-11 in 2019 could represent ongoing production and use of CFC-11, albeit at reduced levels compared to the previous few years, but also probably reflect contributions from foam banks created with new production since 2010 (ref. ${ }^{4}$; Extended Data Fig. 8).

\section{Estimating enhanced production and banks}

While atmospheric observations provide a straightforward way to derive global emissions, an estimate of production magnitudes and additions to banks that accounts for the emission enhancement requires additional information that was recently reassessed ${ }^{4}$. That TEAP study concluded that unreported production after 2010 was most probably used to manufacture closed-cell foams. Production magnitudes associated with the multiple estimates of emission enhancements (Extended Data Figs. 7, 8) were derived by estimating the unreported production required to match excess emissions after 2012 given ranges for emissive losses during CFC production (4-10\%) and the installation of closed-cell foams (17-35\%) (ref. ${ }^{4}$ ), although here we consider an upper limit of $50 \%$ for installation losses to capture the possibility of poor industry practices for formulating and producing foams. These values nominally suggest initial multiples for new production vs enhanced emission of 1.7 to 4 . For the emission enhancements derived relative to the linear fit to 2002-2012 emissions or TEAP*, mean unreported production during 2013-2018 is in the range 25-100 $\mathrm{Gg} \mathrm{yr}^{-1}$, which encompasses the $40-70 \mathrm{Gg} \mathrm{yr}^{-1}$ of unreported production estimated previously ${ }^{4}$ (Extended Data Fig. 8). The 'most likely' TEAP scenario suggests unreported production in excess of $100 \mathrm{Gg} \mathrm{yr}^{-1}$, which, if true, would represent substantially more CFC production than was reported by A5 countries during their peak reporting year of $1997\left(47 \mathrm{Gg} \mathrm{yr}^{-1}\right.$; ref. $\left.^{4}\right)$.

Additions to banks were derived as the cumulative sum of production enhancements minus emissions. We estimate additions to CFC-11 banks from unreported production of between $90 \mathrm{Gg}$ and $725 \mathrm{Gg}$ CFC11 by the end of 2019 for the emission scenarios that were consistent with observationally derived emissions before 2010. The lower end of this range is associated with high levels of emissions during production and installation of the newly produced CFC-11 and small emission enhancements above expectations, whereas the high end of this range is implied by small emission losses associated with new production and larger emission enhancements. While certain combinations of parameter values in the TEAP inventory model, together with a CFC-11 lifetime at its lower limit could suggest larger additions to CFC-11 banks by 2020 (for example, >900 Gg; Extended Data Fig. 8), we estimate that they are less likely, given the reasons discussed above. Furthermore, based on a range of considerations and very different observational constraints, an increase in the CFC-11 bank in eastern China of up to 112 Gg CFC-11 has been estimated through to 2019 (ref. ${ }^{25}$ ), which is more consistent with the lower range of global bank increases, considering that this region accounts for about half of global excess emissions since 2013 (refs. ${ }^{1,3,25}$ ).

\section{Data availability}

NOAA data used in this study are available at https://www.esrl.noaa. gov/gmd/dv/data/index.php?category=Halocompounds and ftp:// ftp.cmdl.noaa.gov/hats/cfcs/cfc11/.AGAGE data can be found at http:// agage.mit.edu. Source data are provided with this paper.

\section{Code availability}

Source code for NCAR Community Earth System Model releases, including WACCM, is distributed through a public Subversion code repository (see http://www.cesm.ucar.edu). The TOMCAT model is a research tool that is available to researchers in the UK funded by the Natural Environment Research Council and other collaborators who have access to suitable computing facilities. The code is not otherwise publicly available. Reasonable requests to use the model should be made to author M.P.C.

30. O'Doherty, S. et al. In situ chloroform measurements at Advanced Global Atmospheric Gases Experiment atmospheric research stations from 1994 to 1998. J. Geophys. Res. 106 (D17), 20429-20444 (2001)

31. Liang, Q. et al. Deriving global $\mathrm{OH}$ abundance and atmospheric lifetimes for long-lived gases: a search for $\mathrm{CH}_{3} \mathrm{CCl}_{3}$ alternatives. J. Geophys. Res. 122, https://doi. org/10.1002/2017JD026926 (2017).

32. Dlugokencky, E. J., Steele, L. P., Lang, P. M. \& Masarie, K. A. The growth rate and distribution of atmospheric methane. J. Geophys. Res. 99, 17021-17043 (1994).

33. Marsh, D. R. et al. Climate change from 1850 to 2005 simulated in CESM1(WACCM). J. Clim. 26, 7372-7391 (2013).

34. Davis, N. A. et al. A comprehensive assessment of tropical stratospheric upwelling in specified dynamics CESM1 (WACCM). Geosci. Model Dev. 13, 717-734 (2020).

35. Chipperfield, M. P. et al. Quantifying the ozone and UV benefits already achieved by the Montreal Protocol. Nat. Commun. 6, 7233 (2015).

36. Chipperfield, M. P. et al. Model sensitivity studies of the decrease in atmospheric carbon tetrachloride. Atmos. Chem. Phys. 16, 15741-15754 (2016).

37. Hersbach, H. et al. The ERA5 Global Reanalysis. Q. J. R. Meteorol. Soc. 2020, 1999-2049 (2020).

38. United Nations Environmental Programme (UNEP)/Technology and Environmental Assessment (TEAP). Report of the TEAP Chiller Task Force. https://ozone.unep.org/sites/ default/files/2019-05/teap_chiller_report_May2004.pdf (ed. L. Kuijpers) (2004).

39. Li, Z. et al. Estimated HCFC-22 emissions for 1990-2050 in China and the increasing contribution to global emissions. Atmos. Environ. 132, 77-84 (2016).

40. Vollmer, M. K. et al. Emissions of ozone-depleting halocarbons from China. Geophys. Res. Lett. 36, L15823 (2009).

41. Rosenlof, K. R. \& Reid, G. C. Trends in the temperature and water vapor content of the tropical lower stratosphere: sea surface connection. J. Geophys. Res. 113, D06107 (2008). 42. Bönisch, H. et al. On the structural changes in the Brewer-Dobson circulation after 2000. Atmos. Chem. Phys. 11, 3937-3948 (2011).

Acknowledgements For sample flask collection and on-site instrument operation, maintenance, and troubleshooting we are grateful to station personnel from NOAA and AGAGE. The operation of AGAGE stations was supported by the National Aeronautics and Space Administration (NASA, USA) (grants NAG5-12669, NNX07AE89G, NNX11AF17G and NNX16AC98G to the Massachusetts Institute of Technology; grants NAG5-4023, NNX07AE87G, NNX07AF09G, NNX11AF15G, NNX11AF16G, NNX16AC97G and NNX16AC96G to the Scripps Institution of Oceanography), the Department for Business, Energy \& Industrial Strategy (BEIS, UK), the National Oceanic and Atmospheric Administration (NOAA, USA), and the Commonwealth Scientific and Industrial Research Organisation (CSIRO, Australia), Bureau of Meteorology (BoM, Australia). We also are indebted to personnel from cooperative institutions involved with flasks sampling in Australia (BoM/CSIRO), Canada (Environment and Climate Change Canada), Ireland (University of Bristol), Israel (Weizmann Inst.), Republic of Korea (Korean Meteorological Administration), the USA (University of Colorado, Harvard University, University of Wisconsin, Scripps Institution of Oceanography), and for logistics support from the US NSF at Summit Greenland, Palmer Antarctica, and South Pole Antarctica Stations. We thank R. Wang for algorithms for extracting background mole fractions from those influenced by recent emission input, and for calculating correlations between CFC-11 data from the American Samoa and Barbados stations and ENSO, and M. Lickley for discussions and results from Bayesian banks analysis. The Community Earth System Modeling project is supported by the National Science Foundation and the Office of Science (BER) of the US Department of Energy. We acknowledge the NOAA Research and Development High Performance Computing Program for computing and storage resources. The TOMCAT modelling work was supported by the NERC SISLAC project (NE/RO01782/1) and simulations were performed on the UK Archer and Leeds Arc HPC machines. This work was funded in part by the NOAA Climate Program Office's AC4 programme. Support was also received from The Met Office Hadley Centre Climate Programme, funded by the UK's Department for Business, Energy and Industrial Strategy and Department for Environment, Food and Rural Affairs. 


\section{Article}

Author contributions S.A.M. led the investigation, provided NOAA GC-MS results, performed interpretive data analysis and box modelling, and wrote the paper with important input from all co-authors. G.S.D., J.D.N., and J.W.E. provided onsite GC-ECD results from NOAA. C.S., J.D.N and J.W.E. provided technical assistance with NOAA flask measurements. R.G.P., R.F.W., P.B.K.

J.M., D.Y., S.O'D., C.H. and P.K.S. provided AGAGE data and scientific insight. M.R. performed

12-box modelling. R.W.P., S.D., M.P.C. and W.F. performed 3D model simulations. E.R. provided

conceptual understanding. B.D.H. ensured accuracy and consistency in standard scales.

A.J.M. performed trajectory calculations. H.W.-T. and C.T. provided inventory modelling and insight.
Competing interests The authors declare no competing interests.

Additional information

Supplementary information The online version contains supplementary material available at https://doi.org/10.1038/s41586-021-03260-5.

Correspondence and requests for materials should be addressed to S.A.M.

Peer review information Nature thanks Martin Dameris, Ross Salawitch and the other,

anonymous, reviewer(s) for their contribution to the peer review of this work. Peer reviewer

reports are available.

Reprints and permissions information is available at http://www.nature.com/reprints. 


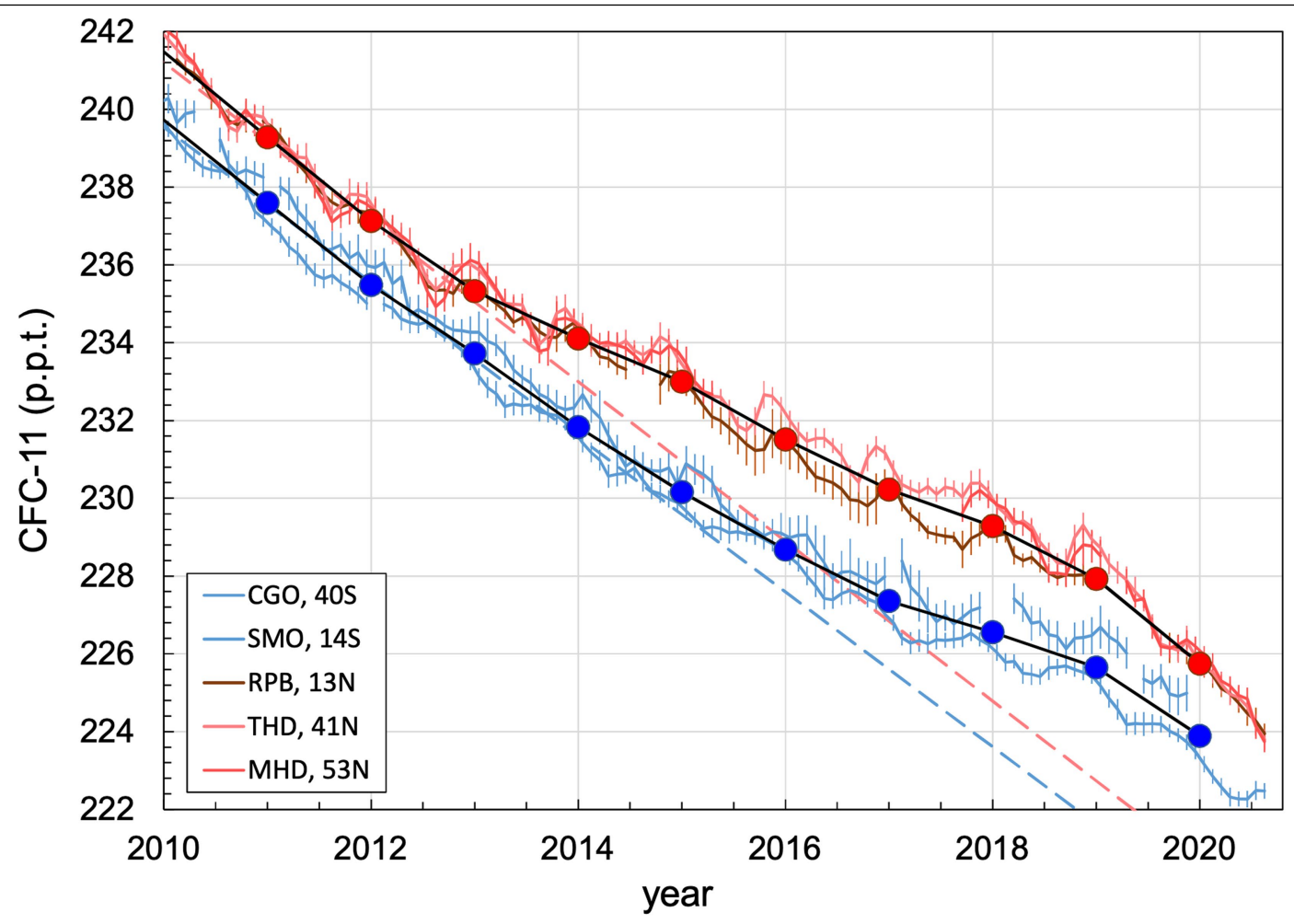

Extended Data Fig. 1 | Measured atmospheric mole fractions of CFC-11 in the AGAGE network. Monthly measured mean mole fractions and standard deviations at 5 remote sites (Extended Data Table 1). Hemispheric annual means centred on 1 January of year given (Northern Hemisphere, red circles;

Southern Hemisphere, blue circles) are derived from results at these 5 sites (Methods). Dashed lines represent projections based on fits to the AGAGE hemispheric means measured during 2002-2012 (Northern Hemisphere, red; Southern Hemisphere, blue). 


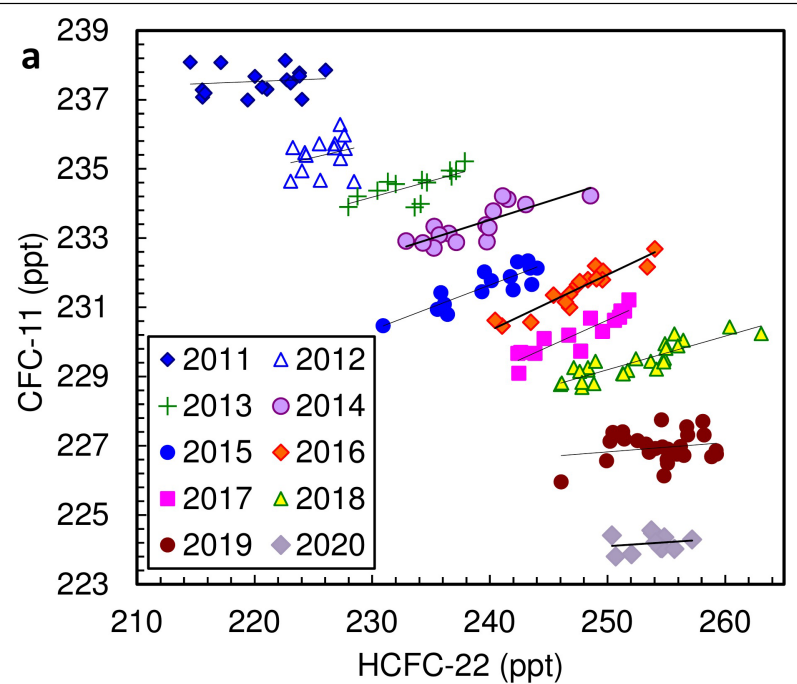

Extended Data Fig. $2 \mid$ Correlations between trace gases measured at a Hawaiian site. a, Mole fraction of CFC-11 and HCFC-22 measured from all flasks during autumns of 2011-2020 at MLO. Each point represents a flask pair mean from all flasks sampled during autumn of the indicated year (fraction of year 0.6-0.9). The linear regression coefficients $r^{2}$ and slopes of these lines are plotted in Fig. 3. b, Linear regression coefficients and slopes from measurements of $\mathrm{CH}_{2} \mathrm{Cl}_{2}$ versus $\mathrm{HCFC}-22$ during autumn at MLO in recent years (similar to Fig. 3, but for these different gases). Results in 2019 and most earlier years show a high correlation for these two gases, which are emitted in

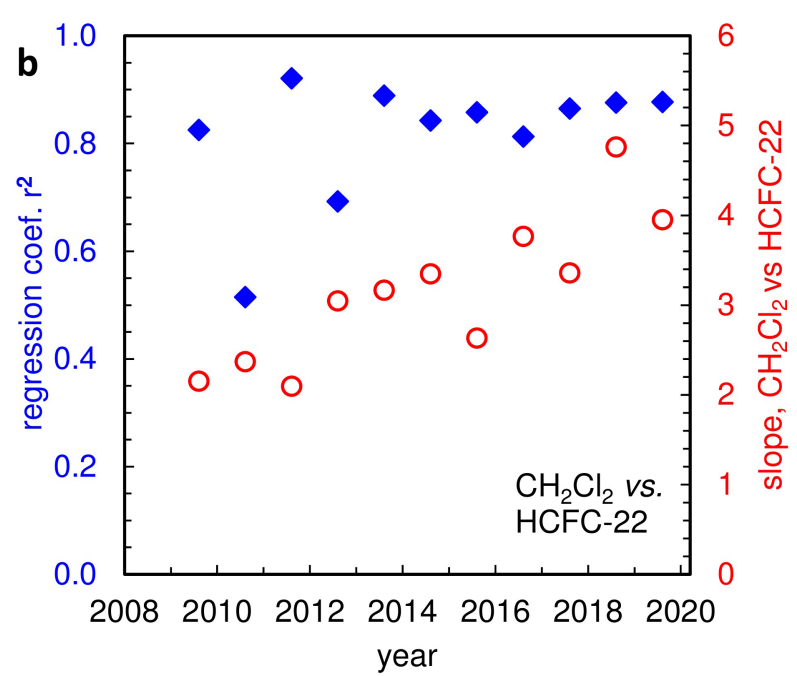

substantial quantities from eastern Asian countries ${ }^{39,40}$. A similar slope is noted between $\mathrm{HCFC}-22$ and $\mathrm{CH}_{2} \mathrm{Cl}_{2}$ for all years considered, including 2019. These results and transport modelling (Extended Data Fig. 3) suggest wind patterns have consistently transported Asian-influenced air to MLO in the autumns of all these years. Despite this consistency in transport, correlations between CFC-11 and HCFC-22 were not observed at MLO during autumn during 2008-2012 and in 2019, implying that eastern Asian emissions of CFC-11 relative to HCFC-22 were reduced during these years. HCFC-22 results are reported on the NOAA-2006 scale, and $\mathrm{CH}_{2} \mathrm{Cl}_{2}$ results are reported on the NOAA-2003 scale. 

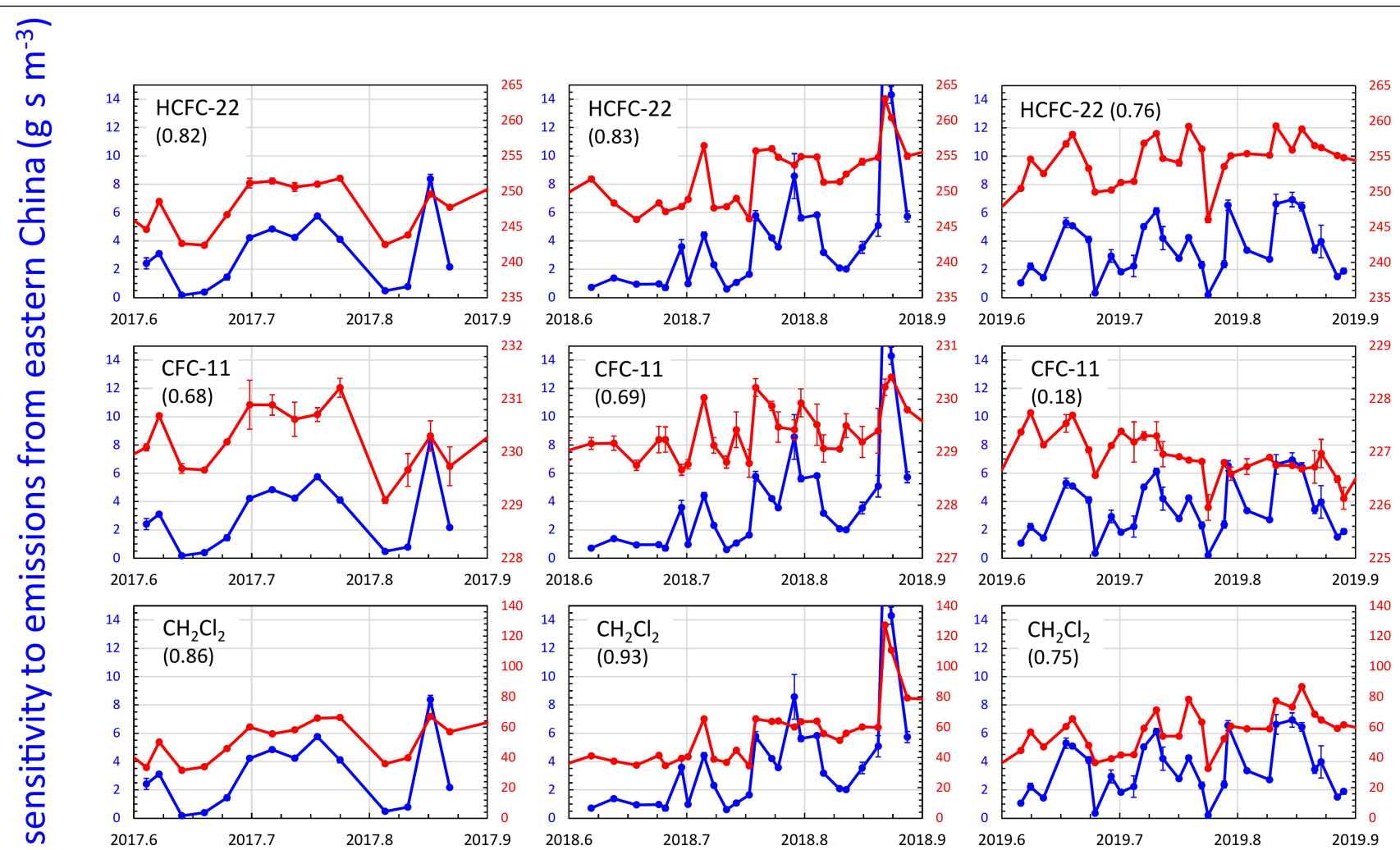

Extended Data Fig. 3 | Surface sensitivities and trace gas mole fractions in air reaching the Mauna Loa Observatory. Measured mole fractions of three trace gases at the Mauna Loa Observatory and the surface sensitivity of those sampling events to emissions from eastern China $\left(20^{\circ} \mathrm{N}\right.$ to $42^{\circ} \mathrm{N}$ latitude and $110^{\circ} \mathrm{E}$ to $122^{\circ} \mathrm{E}$ longitude) are shown for the autumn of 2017,2018 and 2019. Three surface sensitivities were calculated with the NAME mode ${ }^{19}$ for a number of regions bordering the Pacific Ocean basin during each of the three hours surrounding a sampling event (Methods). The mean surface sensitivity magnitudes are plotted in all panels on the same scale (blue lines; left-hand axis; units of $\mathrm{g} \mathrm{s} \mathrm{m}^{-3}$ after being multiplied by $1 \times 10^{9}$ ) and uncertainties represent 1 s.d. of the three sensitivities calculated for each sampling event. These surface sensitivities are the time integrated air concentration simulated within the surface layer $(0-2,000 \mathrm{~m})$ over this region during the 30 days before each sampling event given a point release at MLO of $1 \mathrm{~g} \mathrm{~h}^{-1}$. Measured flask pair mean mole fractions (red symbols and lines, right-hand $y$-axis; uncertainties represent 1 s.d. of the measured mole fraction in the simultaneously sampled flasks) are plotted on scales having the same values ( $\mathrm{HCFC}-22$ and $\mathrm{CH}_{2} \mathrm{Cl}_{2}$ ) or dynamic range (CFC-11) each year. Correlation coefficients $(r)$ are given in parentheses. Although the figure shows sensitivity magnitudes calculated only for eastern China $\left(20^{\circ} \mathrm{N}\right.$ to $42^{\circ} \mathrm{N}$ latitude and $110^{\circ} \mathrm{E}$ to $122^{\circ} \mathrm{E}$ longitude) owing to the findings of Rigby et al. ${ }^{3}$, similar time- and compound-dependent patterns are derived for neighbouring eastern Asian regions and confirms that a precise spatial attribution of these regional emission changes is prevented by the large distance between MLO and eastern Asia. In samples collected at MLO having enhanced surface sensitivity to eastern China and these neighbouring regions, strong correlations are observed in all three years between measured mole fractions of HCFC-22 and $\mathrm{CH}_{2} \mathrm{Cl}_{2}$ (Extended Data Fig. 2), chemicals known to be emitted from this region in large quantities. This indicates that wind patterns consistently transported Asian-influenced air to MLO in autumn of all these years. Enhancements of CFC-11 in samples having enhanced surface sensitivity to eastern China and neighbouring regions, however, are observed only in 2017 and 2018. By 2019 CFC-11 enhancements are no longer measureable above instrumental noise (about $0.2 \mathrm{ppt}$ ) and CFC-11 mole fraction variations are no longer correlated with surface sensitivities derived for eastern China and neighbouring regions. 

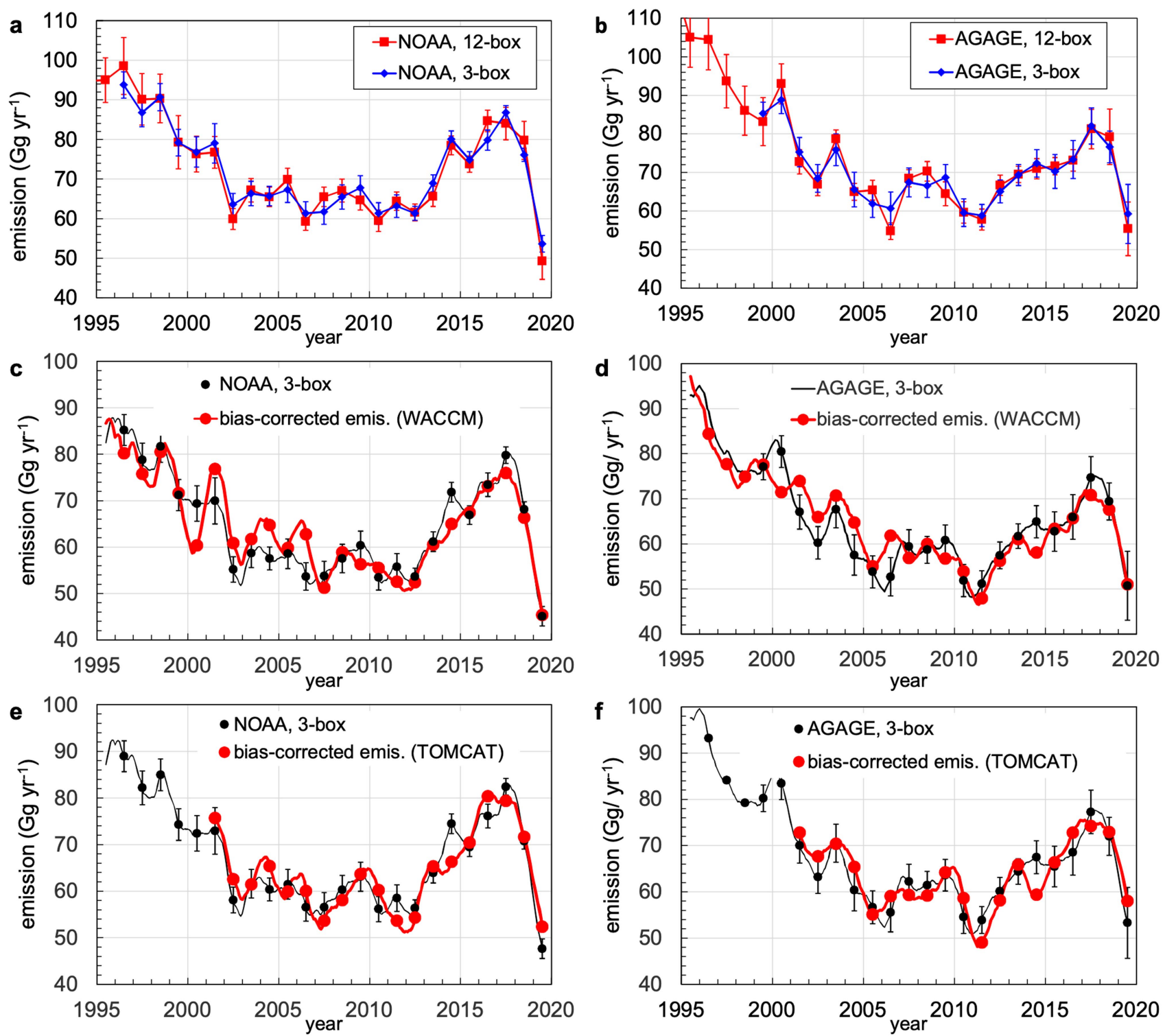

Extended Data Fig. 4 | The sensitivity of observationally derived global CFC-11 emissions to different factors. Top panels show global CFC-11 emission derived with a 12-box or 3-box approach, assuming a constant loss frequency $\left(1 / 52 \mathrm{yr}^{-1}\right)$ and dynamics using: $\mathbf{a}$, NOAA data or $\mathbf{b}$, AGAGE data. Middle and lower panels show emissions derived with the 3-box model applied to data from NOAA (c and $\mathbf{e}$ ) or AGAGE (d and $\mathbf{f}$ ). Biases arising from variations in atmospheric dynamics estimated from both WACCM (56-yr lifetime; $\mathbf{c}$ and d) and TOMCAT 3D models (54-yr lifetime; $\mathbf{e}$ and $\mathbf{f}$ ) are applied to the NOAA- and AGAGE-derived emissions. Results indicate that for all methods of estimation, the general pattern of emission changes over the past decade is robust, including the substantially reduced emissions in 2019. While year-to-year

changes estimated from remote-atmosphere observations with 3- or 12-box models are typically within 1-s.d. uncertainties, biases associated with varying dynamics fall outside that uncertainty range in some years. For emissions derived with the 12-box model ( $\mathbf{a}$ and $\mathbf{b}$ ), emissions were inferred in each semi-hemisphere and season with a least-squares approach, and subsequently were summed to global annual means $\mathrm{s}^{1,3}$. Monthly baseline mole fractions were used in the inversion from AGAGE or NOAA data. The uncertainty on these mole fractions was estimated based on the bootstrapping approach for estimating annual, global mean mole fractions, described above, but multiplied by a factor of $\sqrt{ } 12$, to account for the monthly, rather than annual, resolution of the measurements input to the inversion. 

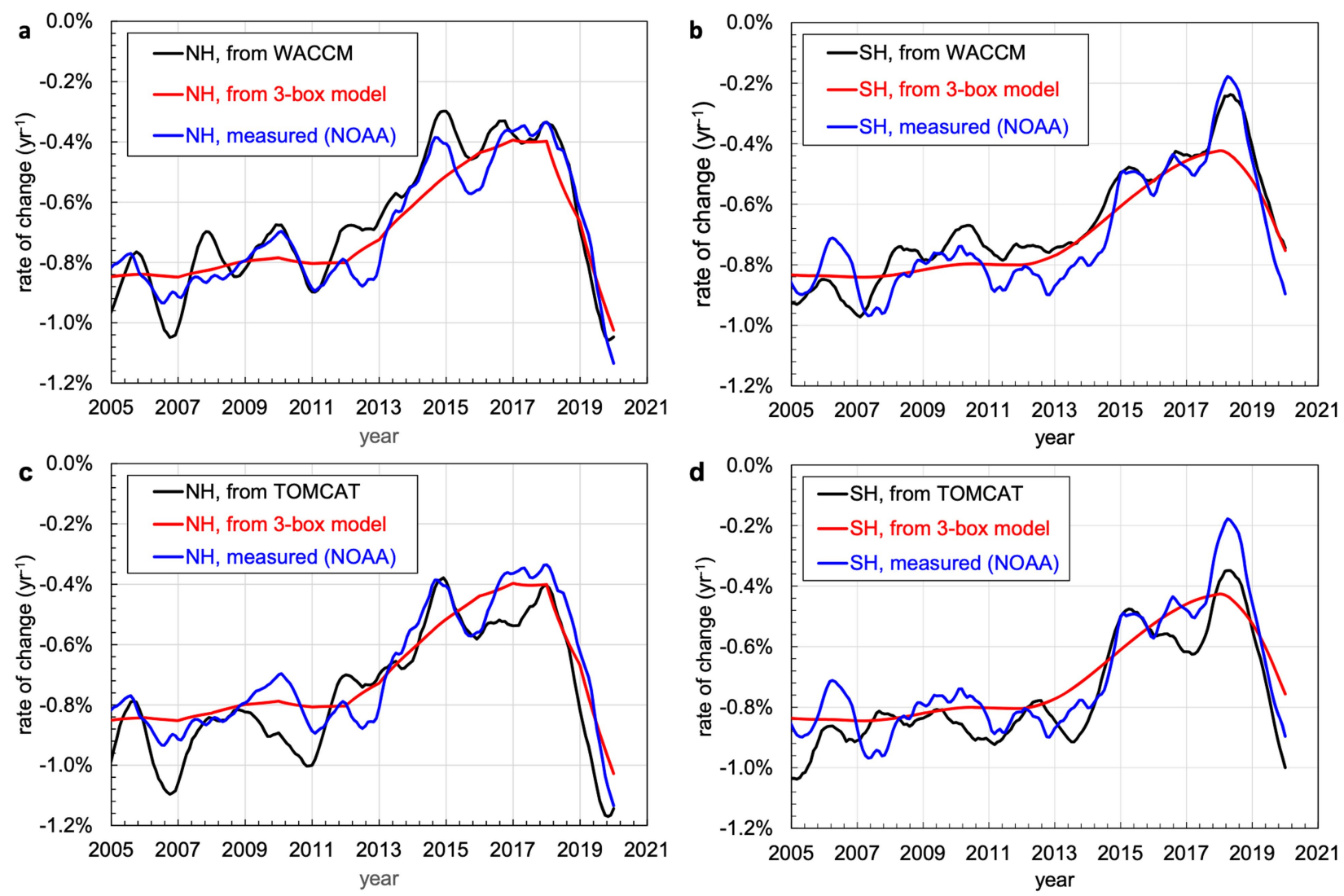

Extended Data Fig. 5 | Annual changes in measured and simulated hemispheric mean surface mole fractions of CFC-11. Rates of mean annual change in mole fraction in the Northern Hemisphere ( $\mathrm{NH}, \mathbf{a}$ and $\mathbf{c})$, and the Southern Hemisphere ( $\mathrm{SH}, \mathbf{b}$ and $\mathbf{d})$. The smoothed emission history derived from an inverse, 3-box analysis of NOAA measurements (Methods) was used in forward runs of the 3-box model (red line) and in the 3D models WACCM (a and b) and TOMCAT (c and d) (black lines), and rates of change in hemispheric mean mole fractions were derived. Mole fraction rates derived by WACCM and TOMCAT and from NOAA observations were from 12-month means, 12 months apart. Much of the measured variability on a 1-3-yr timeframe is captured by the 3D model simulations, despite the smoothly varying emission used as

input. The results suggest that much of this observed variability is not measurement noise or inaccuracies in maintaining calibration consistency, but instead reflects real variability in dynamics that is captured in these 3D model simulations. Measured variability not reproduced by the 3D models could represent the influence of short-term changes in emissions not captured by the smoothly varying emission input or measurement errors. The variations in derived rates in the two hemispheres most of ten co-vary, suggesting that this variability is associated with vertical exchange between the troposphere and stratosphere or stratospheric dynamics (such as the quasi-biennial oscillation ${ }^{20}$ ) as opposed to variations in tropospheric exchange between the hemispheres. 


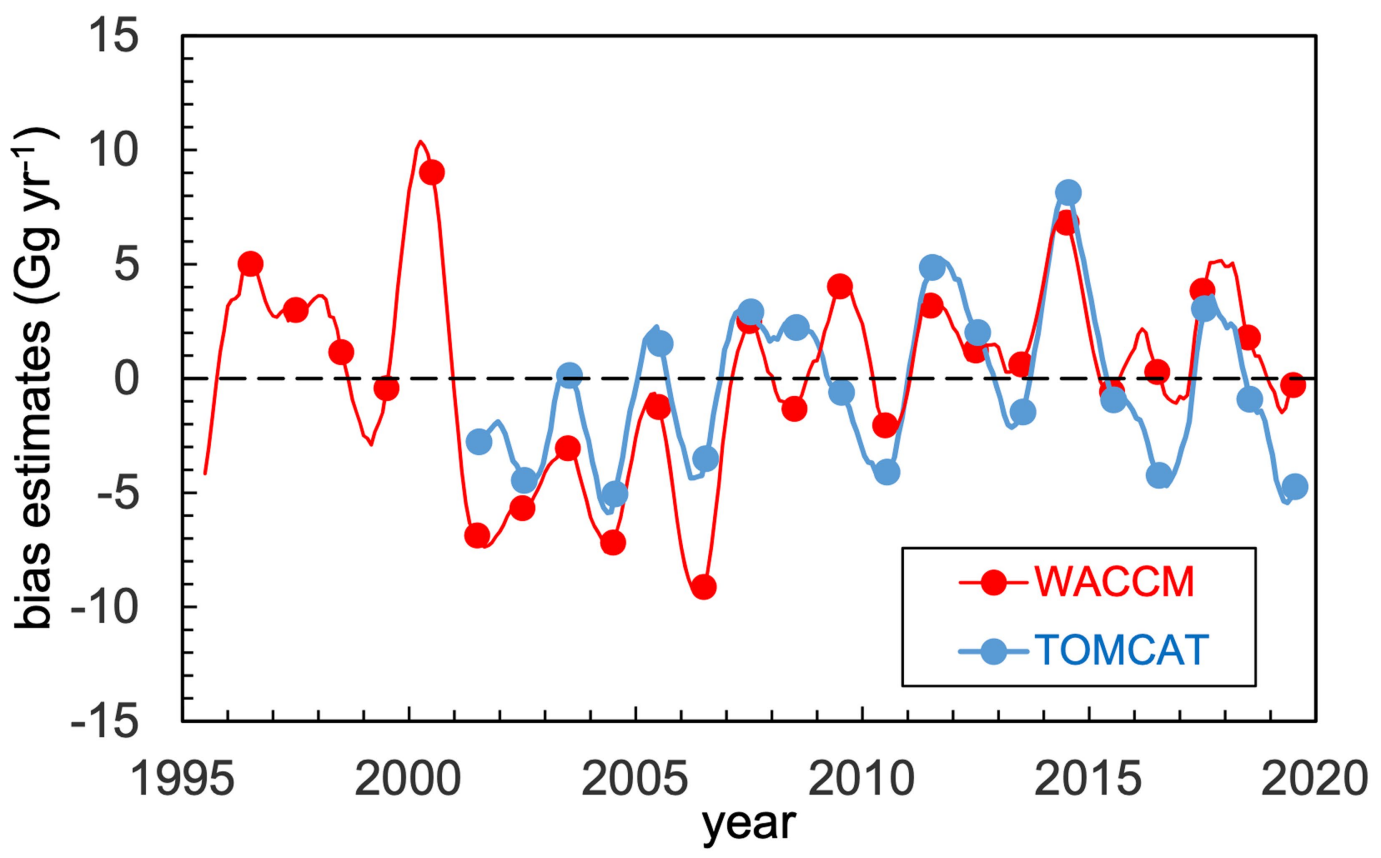

Extended Data Fig. 6 | Estimated bias on global emissions derived from atmospheric data without consideration of inter-annual variability in dynamics. These biases were estimated from 3D model simulations from WACCM (red) and TOMCAT (blue) (see Methods) and represent 12-month smoothed results (line) and calendar year estimates (filled circles). The bias implied in year-to-year changes in global emissions derived without considering variability in dynamics is $5 \pm 4 \mathrm{Gg} \mathrm{yr}^{-1}$ (1 s.d.) on average through this period, but is as high as $16 \mathrm{Gg} \mathrm{yr}^{-1}$ (WACCM; $9 \mathrm{Gg} \mathrm{yr}^{-1}$ in TOMCAT). By comparison, uncertainties in annual emissions derived from consideration of measurement repeatability, calibration stability, and site representation errors during this time period are 2-4 $\mathrm{Gg} \mathrm{yr}^{-1}$ (for example, error bars in Extended Data Fig. 4). For calendar year mean values derived from the two models, the difference in the magnitude of bias estimated from these two 3D models since 2001 is $3.0 \mathrm{Gg} \mathrm{yr}^{-1}$ (1 s.d.); for mean emissions estimated over 4-5-yr periods, the difference is $1.1 \mathrm{Gg} \mathrm{yr}^{-1}$ (1s.d.). The bias-corrected results indicate that dynamics accelerated the decline in CFC-11 mole fractions and global emission after 2018, implying that the emission decrease from 2018 to 2019 is overestimated by up to $4 \mathrm{Gg} \mathrm{yr}^{-1}$ without consideration of variable dynamics. The shift to negative bias following 2000 that persisted until 2006 and is captured by both models is a result of a known perturbation to stratospheric circulation ${ }^{24,41,42}$. This rapid acceleration in 2000 of the lower branch of the Brewer-Dobson circulation gradually diminished over the following six years and is believed to have been caused by anomalous tropical sea surface temperatures but is still not well understood ${ }^{41}$. The results suggest that the persistent increase in stratosphere-troposphere exchange over this period resulted in greater transport of CFC-11-depleted air to the troposphere and subsequently more negative growth rates than would have occurred without this transport change. 


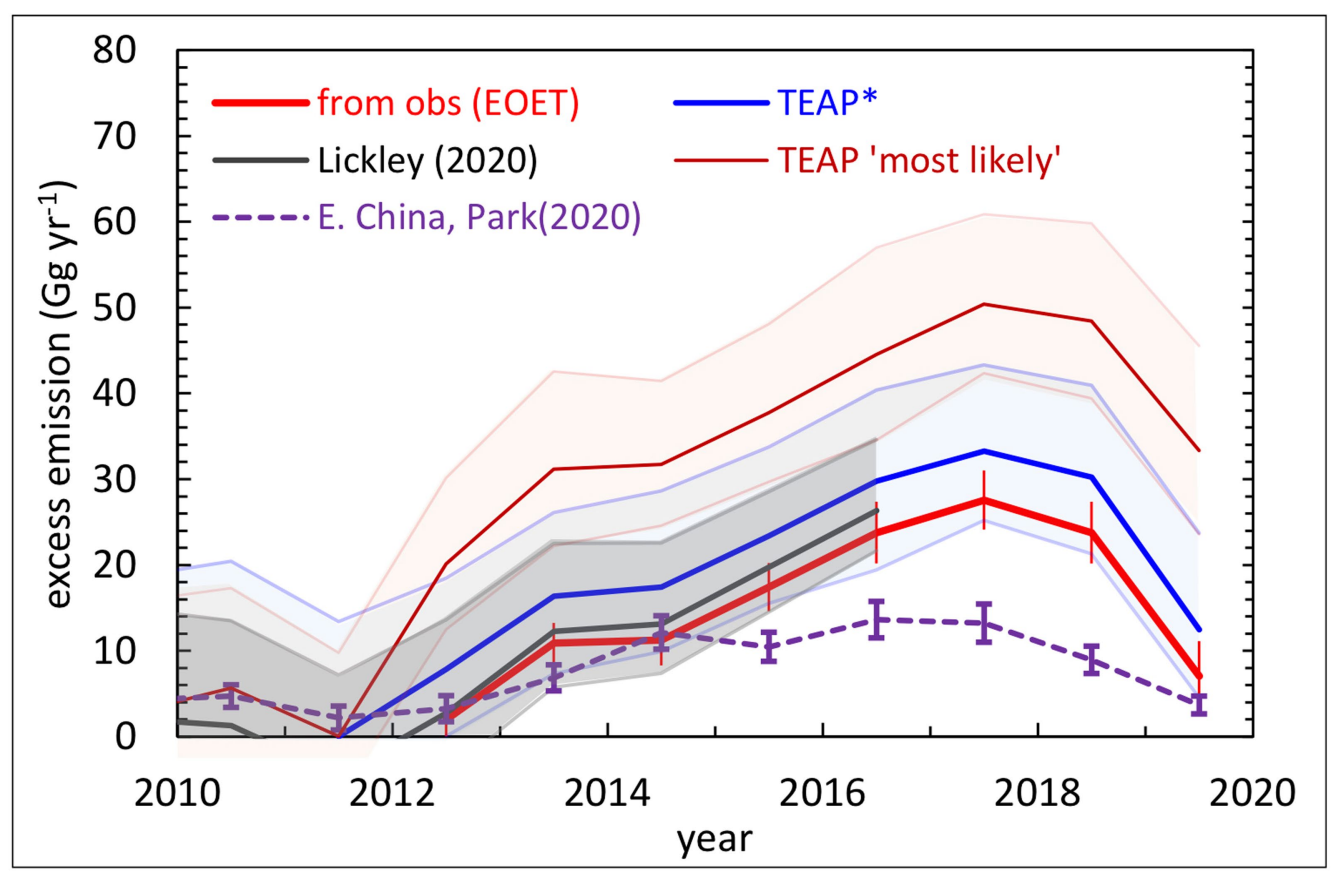

\section{Excess emissions from figure $\left(G g \mathrm{yr}^{-1}\right)$ : \\ Relative to: \\ EOET \\ TEAP* \\ TEAP, 'most likely' \\ $7(2,13)$ \\ $12(5,24)$ \\ $34(24,46)$}

Extended Data Fig. 7 | Inferred enhancements in global and regional emissions above expectations (excess emission). Excess global emissions are derived from the difference between measurement-derived emissions (NOAA and AGAGE combined estimate, corrected for dynamics) and the emission expectations considering no post-2010 production that are shown in Fig. 4. Expectations are derived from: (1) an extrapolated linear fit to observationally derived emissions during 2002 to 2012 (red solid line, uncertainties represent 1 s.d. of extrapolation plus dynamical corrections; labelled as EOET (extrapolated observed emission trend)); (2) emissions associated with the modified TEAP inventory analysis (TEAP*; blue line; see Methods); (3) those from a combined inventory and observational Bayesian analysis $^{15}$ (labelled 'Lickley (2020)', with grey line and shaded region representing 95\% confidence interval); and (4) those from TEAP's 'most likely' inventory model result ${ }^{4}$ (brown line). Shaded regions associated with the two TEAP model results represent the influence of CFC-11 lifetime ranging from $50 \mathrm{yr}$ to $60 \mathrm{yr}$ (Methods). For clarity, quantitative estimates of excess emission

\author{
2014-2018 mean (low, high) \\ $21(17,24)$ \\ $25(18,37)$ \\ $44(35,55)$
}

from these data are tabulated below the chart for different periods, and some of these values are quoted in the main text. Excess regional emissions have been estimated from eastern China ${ }^{25}$ (dashed purple line labelled 'E. China, Park (2020)' and are based on an inverse analysis of pollution plume concentrations of CFC-11 measured at two sites in eastern Asia. While global excess emissions have substantial uncertainties, the results from eastern China suggests that this region accounted for a larger fraction of the global excess emission before 2015 than after it. An excess emission of $5 \mathrm{Gg} \mathrm{yr}^{-1}$ would represent a $10 \%$ enhancement in global emissions $\left(52 \pm 5, \pm 10 \mathrm{Gg} \mathrm{yr}^{-1}\right)$ in 2019 , which is within the range of relative enhancements for CFC-11 banks we estimate (90-725 Gg; Extended Data Fig. 8) when considered relative to a 1,200-1,600 Gg bank in recent years ${ }^{3,4,15}$. Larger excess emissions in 2019 may suggest substantially larger increases in the CFC-11 foam bank from recent production, but also could reflect continued emissions from ongoing production and foam manufacturing. 

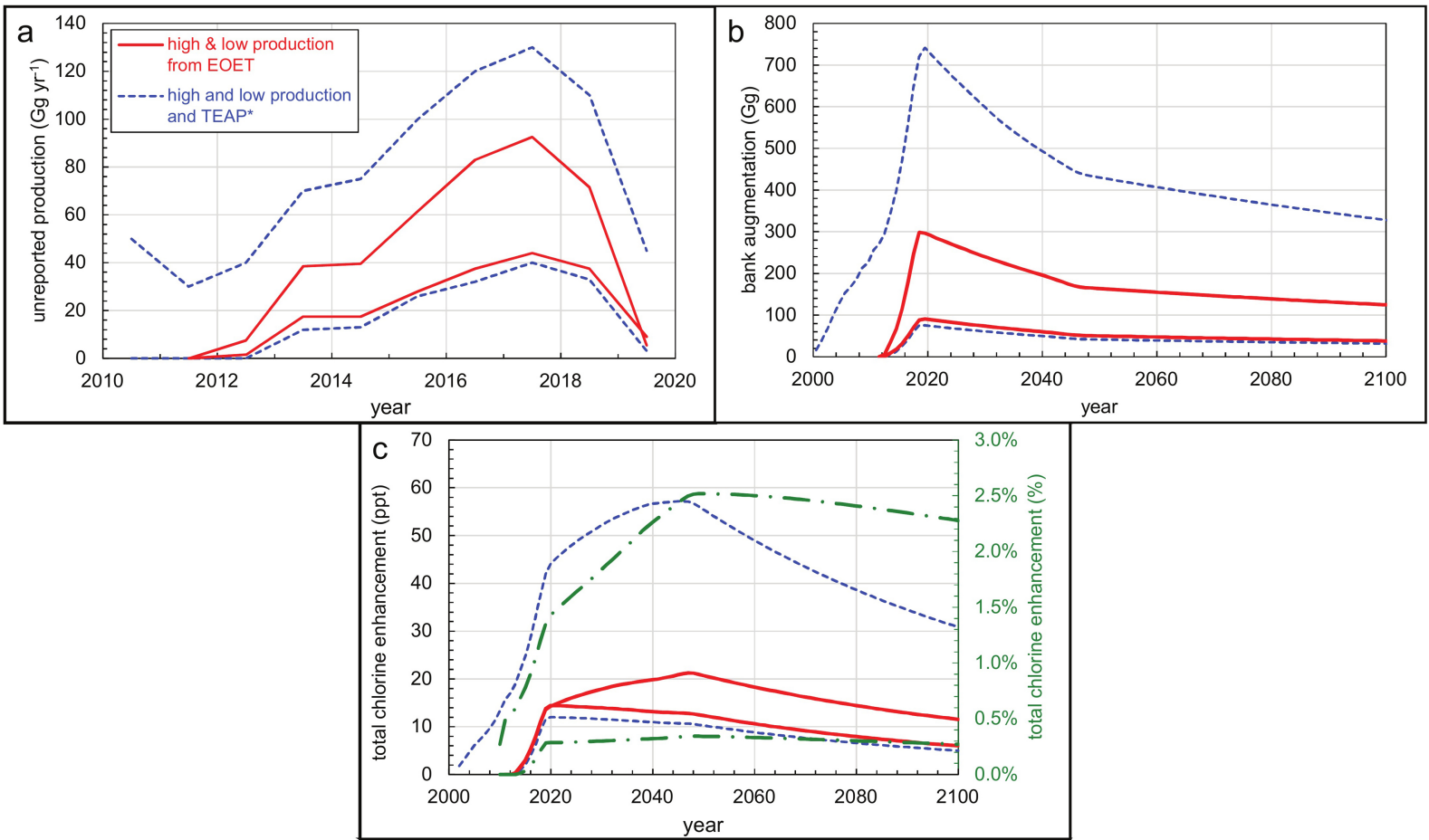

Extended Data Fig. 8 | Inferred enhancements in CFC-11 production, CFC-11 banks and total atmospheric chlorine. a, Production magnitudes derived from the emission enhancements in Extended Data Fig. 7 (EOET and TEAP*) assuming a range of emissions during CFC-11 production (4-10\%), use of this production entirely for closed-cell foam manufacturing, and a range of emissions during the closed-cell foaming process of $21-50 \%$ (ref. ${ }^{4}$; Methods). b, Additions to the foam bank are derived in the TEAP model as a result of unreported production magnitudes shown in a.c. Total atmospheric chlorine enhancements were derived from emission enhancements in Extended Data Fig. 7 and, for future years, from augmented banks (b) using a simple box model of the atmosphere. Upper and lower relative contributions to total atmospheric chlorine were derived by dividing the high and low results from
TEAP* (blue dashed lines) by total chlorine in a recent projection ${ }^{16}$ (green dot-dashed lines plotted relative to the right-hand $y$-axis scale). Although emissions changes observed to date do not indicate unexpected enhancements in CFC-12 as a result of co-production with CFC-11 (Extended Data Fig. 9), total $\mathrm{Cl}$ enhancements shown above could be up to one-third higher for typical co-production rates (70\% CFC-11/30\% CFC-12 by weight), although much smaller rates of CFC-12 co-production are also possible ${ }^{4}$. Higher values are derived from the TEAP 'most likely' scenario (67-180 $\mathrm{Gg} \mathrm{yr}^{-1}$ peak production in 2017 and $160-950 \mathrm{Gg}$ bank in 2020) but are not shown here for clarity. For reference, reported total global production of CFC-11 peaked in the late $1980 \mathrm{~s}_{\text {at }} 430 \mathrm{Gg} \mathrm{gr}^{-1}$ and in the Article 5 Parties to the Montreal Protocol (developing countries) it peaked in 1997 at $47 \mathrm{kt} \mathrm{yr}^{-1}$ (ref. ${ }^{4}$ ). 


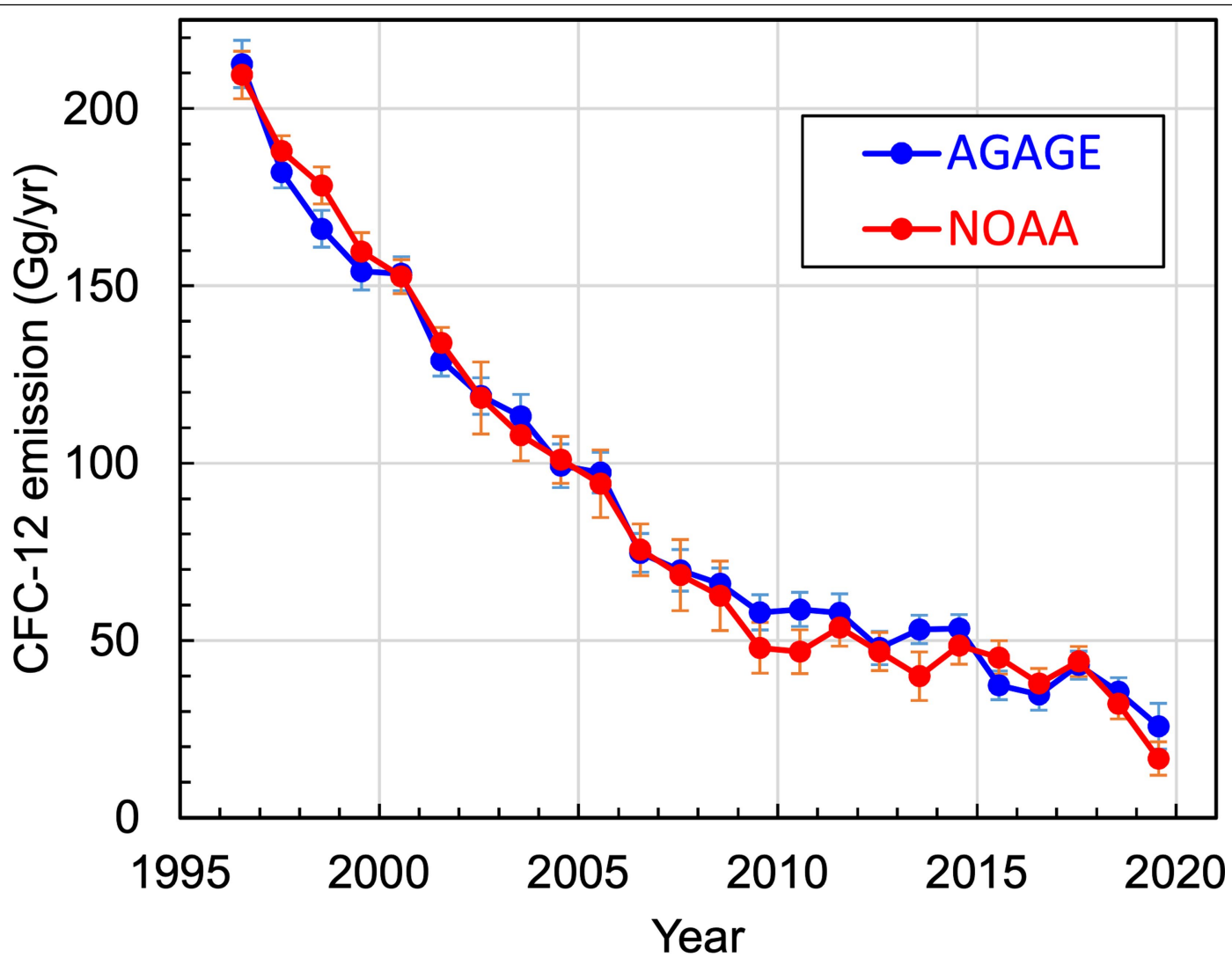

Extended Data Fig. 9 | Global emissions of CFC-12 derived from atmospheric observations. Global emissions were derived from NOAA and AGAGE measurements using methods similar to those described for CFC-11 (Methods, Extended Data Fig. 4). These emissions were calculated with a CFC-12 lifetime of $102 \mathrm{yr}\left(\right.$ ref. $\left.^{29}\right)$. Uncertainties (1 s.d.) shown reflect only the influences of measurement repeatability, atmospheric variability and representation errors associated with the finite number of sampling locations within each semi-hemisphere. As a result, differences in results from the two measurement networks probably reflect errors in instrument operations or standardization over time. Because production of CFC-11 typically involves co-production of CFC-12, any increases in CFC-12 emissions above their expected values since 2012 could provide additional evidence of renewed CFC production ${ }^{4}$. Substantial co-production and emission of CFC- 12 would imply larger impacts of the renewed CFC production on future stratospheric ozone than are derived from the consideration of CFC-11 alone. Uncertainties in expected emission changes over the past decade and in annual estimates of global CFC-12 emission (4-10 $\left.\mathrm{Gg} \mathrm{yr}^{-1}\right)$, however, have so far confounded the detection of unusual enhancements in CFC-12 emissions in recent years ${ }^{4,15}$. Furthermore, changes in CFC-12 emissions from eastern Asia since 2010 $\left(<5 \mathrm{Gg} \mathrm{yr}^{-1} ;\right.$ ref. $\left.^{25}\right)$ would be difficult to detect in global trends given comparable or larger uncertainties in annual estimates of global CFC-12 emission $\left(4-10 \mathrm{Gg} \mathrm{yr}^{-1}\right)$. 


\section{Article}

Extended Data Table 1 | Measurement site locations, instrumental methods and associated network

Semi-

Hemisphere Site lat \& long Network Method

$30-90^{\circ} \mathrm{N}$

\begin{tabular}{|c|c|c|c|}
\hline ALT & $82.45^{\circ} \mathrm{N}, 62.51^{\circ} \mathrm{W}$ & NOAA & flask/ECD, flask/MS \\
\hline SUM & $72.58^{\circ} \mathrm{N}, 38.45^{\circ} \mathrm{W}$ & NOAA & flask/ECD, flask/MS \\
\hline BRW & $71.32^{\circ} \mathrm{N}, 156.61^{\circ} \mathrm{W}$ & NOAA & onsite/ECD, flask/ECD, flask/MS \\
\hline \multirow[t]{2}{*}{ MHD } & $53.33^{\circ} \mathrm{N}, 9.91^{\circ} \mathrm{W}$ & & AGAGE onsite/ECD \\
\hline & & NOAA & flask/ECD, flask/MS \\
\hline \multirow[t]{2}{*}{ THD } & $41.05^{\circ} \mathrm{N}, 123.15^{\circ} \mathrm{W}$ & AGAGE & onsite/ECD \\
\hline & & NOAA & flask/ECD, flask/MS \\
\hline NWR & $40.05^{\circ} \mathrm{N}, 105.59^{\circ} \mathrm{W}$ & NOAA & onsite ECD, flask/ECD, flask/MS \\
\hline
\end{tabular}

$0-30^{\circ} \mathrm{N}$

$\begin{array}{lll}\text { KUM } & 19.52^{\circ} \mathrm{N}, 154.81^{\circ} \mathrm{W} & \text { NOAA } \\ \text { MLO } & 19.54^{\circ} \mathrm{N}, 155.58^{\circ} \mathrm{W} & \text { NOAA } \\ \text { RPB } & 13.17^{\circ} \mathrm{N}, 59.43^{\circ} \mathrm{W} & \text { AGAGE }\end{array}$

flask/ECD, flask/MS

onsite $E C D$, flask/ECD, flask/MS

onsite ECD

$0-30^{\circ} \mathrm{S}$

SMO $\quad 14.25^{\circ} \mathrm{S}, 170.57^{\circ} \mathrm{W} \quad$ AGAGE

onsite ECD

NOAA

onsite $E C D$, flask/ECD, flask/MS

$30-90^{\circ} \mathrm{S}$

$\begin{array}{lll}\text { CGO } & 40.68^{\circ} \mathrm{S}, 144.69^{\circ} \mathrm{E} & \text { AGAGE } \\ & & \text { NOAA } \\ \text { PSA } & 64.77^{\circ} \mathrm{S}, 64.05^{\circ} \mathrm{W} & \text { NOAA } \\ \text { SPO } & 90^{\circ} \mathrm{S} & \text { NOAA }\end{array}$

onsite ECD

flask/ECD, flask/MS

flask/ECD, flask/MS

onsite ECD, flask/ECD, flask/MS

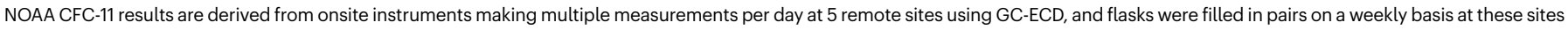
and others (12 in total). These flasks are analysed in a central laboratory using GC-ECD and GC-MS. AGAGE CFC-11 results are derived from onsite GC-ECD instrumentation making up to 36 measurements per day at 5 remote sites across the globe. At 4 of the AGAGE measurement locations, NOAA flask pairs were also collected approximately once per week. Calibration scales are prepared and maintained independently within AGAGE and NOAA using dissimilar methods, and consistency over time in those scales is also independently maintained. NOAA data are

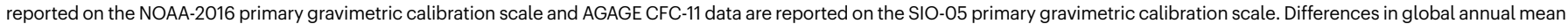
mole fractions estimated for CFC-11 between these two networks averaged $0.01 \pm 0.16 \%$ during $2000-2019$ (NOAA/AGAGE), but they include a drift over time that leads in part to slightly different emissions and emission increases from 2012-2017 (Extended Data Fig. 4). While the global mean difference was $-0.12 \pm 0.04 \%$ during $2008-2012$, it was $+0.27 \pm 0.04 \%$ during

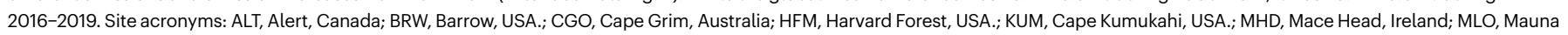
Loa, USA.; NWR, Niwot Ridge, USA.; PSA, Palmer Station, Antarctica; RPB, Republic of Barbados, SMO, American Samoa; SPO, South Pole Station, Antarctica; SUM, Summit Greenland. 